\title{
Atlantic Zonal Mode-Monsoon Teleconnection in a Warming Scenario
}

Sabeerali C. T

New York University - Abu Dhabi Campus

Ajaya Mohan Ravindran ( $\nabla$ ajaya.mohan@nyu.edu )

New York University - Abu Dhabi https://orcid.org/0000-0002-4513-4905

Praveen V

New York University - Abu Dhabi Campus

\section{Research Article}

Keywords: Indian Summer Monsoon, Atlantic Zonal Mode, AZM-Monsoon 26 Teleconnection, CMIP6 Models, Global Warming

Posted Date: March 1st, 2021

DOI: https://doi.org/10.21203/rs.3.rs-169135/v1

License: (c) (1) This work is licensed under a Creative Commons Attribution 4.0 International License. Read Full License 


\section{Atlantic Zonal Mode-Monsoon Teleconnection in a}

2 Warming Scenario

C. T. Sabeerali - R. S. Ajayamohan •

4 V. Praveen

6 Received: date / Accepted: date

C. T. Sabeerali

Center for Prototype Climate Modelling, New York University Abu Dhabi, P.O. Box 129188, Abu Dhabi, UAE

E-mail: sabeer@nyu.edu

R. S. Ajayamohan

Center for Prototype Climate Modelling, New York University Abu Dhabi, P.O. Box 129188, Abu Dhabi, UAE

E-mail: Ajaya.Mohan@nyu.edu

V. Praveen

Center for Prototype Climate Modelling, New York University Abu Dhabi, P.O. Box 129188, Abu Dhabi, UAE

E-mail: praveen.v@nyu.edu 
7 Abstract The dominant interannual SST variability in the eastern equatorial 8 Atlantic referred to as the Atlantic Zonal Mode (AZM), which peaks in boreal 9 summer impacts global weather patterns. The cold (warm) phase of this ocean10 atmospheric coupled phenomenon enhances (weakens) the intensity of the Indian 11 summer monsoon rainfall (ISMR). Observational studies show a strengthening 12 relationship between AZM and ISMR in recent decades, providing a predictive 13 signal for the ISMR. However, a suite of Coupled Model Intercomparison Project 14 Phase 6 (CMIP6) model simulations in the highest emission scenario (SSP58.5) 15 show a weakening relationship between ISMR and AZM in the future (2050-2099). ${ }_{16}$ The strengthening of atmospheric thermal stability over the tropical Atlantic in the 17 warming scenario weakens the associated convection over the eastern equatorial 18 Atlantic in response to the warm phase of AZM. This leads to weakening velocity 19 potential response over the Indian subcontinent, resulting in a weak AZM-ISMR

20 relationship. There is no convincing evidence to indicate that either the tropical ${ }_{21}$ Atlantic SST bias or the AZM-ISMR teleconnection bias plays a crucial role in the 22 potential weakening of this relationship. These results imply that ISMR prediction 23 will become more challenging in a warming scenario as one of the major external boundary forces that influence monsoon weakens.

25 Keywords Indian Summer Monsoon · Atlantic Zonal Mode · AZM-Monsoon

26 Teleconnection · CMIP6 Models · Global Warming 
46 ocean and its associated teleconnection.

India receives $\sim 80 \%$ of its annual rainfall during boreal summer months. A large majority of people in an agrarian-based society like India depend on the seasonal rainfall. The year to year variability of the seasonal quantum of rainfall is significant as the country's economy and gross domestic product (GDP) are dependent on the amount of rainfall received during this period (Gadgil and Gadgil, 2006). This year to year variability (also known as interannual variability (IAV)) in the Indian summer monsoon rainfall (ISMR) is partly controlled by slowly varying modes of variability in the tropical ocean (Ajayamohan and Goswami, 2000; Goswami and Ajayamohan, 2001; Krishnamurthy and Shukla, 2007). The El Niño-Southern Oscillation (ENSO) in the tropical Pacific (Rasmusson and Wallace, 1983; Shukla, 1987; Philander, 1990), the Indian Ocean Dipole (IOD) in the tropical Indian Ocean (Saji et al, 1999; Ashok et al, 2001) and the Atlantic Zonal Mode (AZM) in the tropical Atlantic (Kucharski et al, 2008; Losada et al, 2010; Kucharski and Joshi, 2017; Sabeerali et al, 2018, 2019) are the major SST modes of variabilities that influences the IAV of ISMR. In addition to these tropical SST variabilities, the SST variations in extra-tropical Pacific and Atlantic Ocean also affects the IAV of ISMR (Chattopadhyay et al, 2015). The seasonal mean ISMR forecasts consequently rely on the skillful prediction of these interannual modes in the tropical

Recently, Sabeerali et al (2018) show that the prediction skill of ISMR improves significantly by correcting the biases in the simulation of tropical Atlantic Zonal Mode (also known as the Atlantic Niño) variability in a coupled model (NCEPCFSv2). Further, observations indicate that the teleconnection between AZM and ISMR strengthens in recent decades (Sabeerali et al, 2019). Both these studies highlight the significance of a realistic simulation of tropical Atlantic variability for the skillful prediction of ISMR. Considering the importance of these teleconnections in predicting ISMR in the present (historical) scenario, it will be intriguing 
55 to see how these variabilities change in a warming scenario. The future changes

56 in the ENSO-ISMR teleconnection and IOD-ISMR teleconnections are explored in 57 previous studies (Li and Ting, 2015; Azad and Rajeevan, 2016; Yeh et al, 2018;

58 Roy et al, 2019; Zheng et al, 2013). However, little attention has been paid to the

59 AZM-ISMR teleconnection and its changes in the future. Here, we analyze the

60 AZM-ISMR teleconnection in the future scenario using a suite of CMIP6 coupled ${ }_{61}$ models that realistically simulates this association in the historical simulations.

The AZM is primarily driven by the Bjerknes feedback mechanism (Bjerknes, 1969) akin to the dynamics responsible for the evolution of ENSO in the tropical Pacific (Zebiak, 1993; Carton and Huang, 1994; Keenlyside and Latif, 2007; Ding et al, 2010; Foltz and McPhaden, 2010; Lübbecke et al, 2010). The SST variability over the eastern equatorial Atlantic exerts a profound impact on the Indian summer monsoon (Kucharski et al, 2008; Pottapinjara et al, 2014, 2016; Kucharski and Joshi, 2017; Sabeerali et al, 2018, 2019). A cold (warm) phase of AZM contributes to enhanced (reduced) rainfall over central India and the Western Ghats. Sabeerali et al (2019) attributed the strengthening of AZM-ISMR teleconnection in recent decades to the increase in the interannual variability of eastern tropical Atlantic SST. The AZM is also found to influence the characteristics of ENSO in the Pacific (Jansen et al, 2009; Wang et al, 2009; Rodríguez-Fonseca et al, 2009; Ding et al, 2012; Keenlyside et al, 2013; Ham et al, 2013; Yang et al, 2018). A few CMIP5 models show a weakening of the AZM-Pacific Ocean teleconnection under global warming (Jia et al, 2019). They attributed the AZM-ENSO weakening to the increase in the thermal stability of the atmosphere in the warming scenario. Here, we examine the AZM-ISMR relationship in a warming scenario by analyzing the state-of-the-art coupled climate model outputs from the CMIP6 archive.

In general, the coupled models show a large bias in simulating and predicting the AZM and its associated teleconnection (Stockdale et al, 2006; Kucharski and Joshi, 2017; Sabeerali et al, 2018). Kucharski and Joshi (2017) show that about half of the CMIP5 models analyzed (16 out of 32 models) fail to capture the observed 
AZM-monsoon teleconnection. The large eastern equatorial Atlantic warm SST bias in coupled models limit the proper simulation of interannual variability of SST (Richter and Xie, 2008; Wahl et al, 2011; Wang et al, 2014; Ding et al, 2015a,b). This SST bias is closely related to the boreal spring tropical Atlantic westerly wind stress and associated deepening of thermocline in eastern equatorial Atlantic (Chang et al, 2007; Richter and Xie, 2008; Tozuka et al, 2011). A significant improvement in the mean SST bias is not evident in the CMIP5 models (Richter et al, 2014). To a certain extent, the AZM prediction skill in coupled models can be improved by correcting these mean SST biases (Ding et al, 2015b). The latest version of coupled models in the Coupled Model Intercomparison Project Phase 6 (CMIP6) offers new opportunities for a more detailed evaluation of AZM and its associated teleconnection in both historical and future simulations.

As mentioned above, the long-term observational datasets show a strengthening relationship between AZM and monsoon in recent decades (Sabeerali et al, 2019). The AZM-ISMR teleconnection provides an additional source of memory for monsoon prediction, a season in advance. The correct representation of AZM and its teleconnection with ISMR in coupled models markedly improves the prediction skill of ISMR (Sabeerali et al, 2018). Hence, how the AZM-ISMR relationship change in future warming scenario is not only a scientific problem but also very relevant for the operational forecasting of monsoon rainfall over India. This study is organized as follows. In section 2, a brief introduction of CMIP6 model experiments and the data used in this study is enlisted, followed by the methodology used. The simulation of AZM and its associated teleconnection with ISMR in the historical simulations is described in Section 3. Section 4 details the projected changes in AZM-ISMR teleconnection in the future. The underlying dynamics causing these changes are also discussed. A brief summary and concluding remarks are provided in Section 5. 


\section{Data and Methods}

\subsection{CMIP6 data}

In this study, we use the monthly outputs of historical simulations for the period 1965-2014 to represent the present-day climate. For the future climate (2050-2099), Shared Socioeconomic Pathways (SSPs) scenario SSP5-8.5 simulations are used. One ensemble member (r1i1p1f1) from 23 models (see Table 1) from the CMIP6 archive (Eyring et al, 2016; O'Neill et al, 2016, 2017) is used for the analysis. In the historical simulations, models are forced with time-dependent observations to simulate the climate of the period 1850-2014 (Eyring et al, 2016). The SSP5-8.5 represents the highest emission scenario (comparable to business as usual RCP8.5 scenario of CMIP5) where the radiative forcing reaches $8.5 \mathrm{Wm}^{-2}$ by the end of the century (2100) (O'Neill et al, 2016).

All the model data is regridded to a common $1^{\circ} \times 1^{\circ}$ regular grid for ease of comparison. The observed monthly SST data originates from the Hadley Centre (HadISST; Rayner et al, 2003) and the gridded high resolution $\left(0.25^{\circ} \times 0.25^{\circ}\right)$ precipitation datasets are from the India Meteorological Department (IMD; Pai et al, 2014).

\subsection{AZM indices}

We define the AZM index as the average seasonal mean (June through August) SST anomalies over the eastern equatorial Atlantic Ocean $\left(5^{\circ} \mathrm{S}-3^{\circ} \mathrm{N}, 20^{\circ} \mathrm{W}-10^{\circ} \mathrm{E}\right)$. A cold (warm) phase of AZM is the year when the normalized AZM index exceeds one negative (positive) standard deviation. Prior to the analysis, we remove the ENSO influence from all the variables following the methodology described in previous studies (Pottapinjara et al, 2016; Sabeerali et al, 2018). For 
$R A I N F A L L_{r e s}(t)=R A I N F A L L(t)-a N I N O 34(t)($ pres $)-b N I N O 34_{r e s}(t)($ prewo1 $)$

instance, the ENSO free component of boreal summer monsoon rainfall anomalies

$\left(R A I N F A L L_{r e s}(t)\right)$ is defined as follows

Where the RAINFALL(t) represents the raw total rainfall anomalies, which include all the variabilities arising from ENSO, IOD, and AZM, etc. The constant $a$ is defined as the slope of regression fit between rainfall and NINO3.4 index in the present monsoon season. The constant $b$ is defined as the least square regression fit between the rainfall and residual of NINO3.4 index in the previous monsoon season which is not correlated with the NINO3.4 index in the present monsoon season. The last term in the equation represents the influence of ENSO of the previous monsoon season on rainfall which is not related to ENSO of the present season.

Here, $N I N O 34_{\text {res }}(t)($ prev $)=N I N O 34(t)($ prev $)-c N I N O 34(t)($ pres $)$.

The constant $c$ is defined as the slop of the least square regression fit between NINO3.4 index in the present and previous monsoon season.

\subsection{Sign-dependent area average}

This study follows a sign dependent area-average of regression and correlation coefficient following Jia et al (2019). This method considers only the statistically significant regression or correlation coefficient grid points and discards the coefficients at other grid points. To check whether the retained values are positive or negative, we first take an area-average of all significant values in the domain of interest. If this area-average value is positive (negative), we repeat the area-averaging by considering only significant positive (negative) coefficients over the region of 
interest. If there is no statistically significant correlation/regression coefficient in an area of interest, we set zero as the average of that region.

\section{AZM-monsoon teleconnection in CMIP6 historical simulations}

The AZM-ISMR relationship from the 23 CMIP6 models is analyzed to identify models that realistically simulate observed teleconnection. To assess the performance of models in simulating the AZM-monsoon relationship, a correlation analysis is conducted between the boreal summer central Indian rainfall anomalies and the tropical Atlantic SST anomalies (Figure 1). Observations show an inverse relationship between central Indian rainfall and SST anomalies over eastern equatorial Atlantic (Figure 1 and Figure 2a) consistent with the previous studies (Kucharski et al, 2008; Pottapinjara et al, 2016; Sabeerali et al, 2018, 2019). Out of 23 CMIP6 models analyzed, a total of 12 models simulate the observed inverse relationship, although the magnitude of correlation values is weak (Figure 1). We term these 12 models as 'good' models and use these model outputs for further analysis and projections in this study. Six models show a positive correlation, whereas five models show no significant relationship between ISMR and AZM (Figure 1). For comparison, we term these six models as 'weak' models (weak in the sense that the models which simulate opposite teleconnection between AZM and ISMR compared to observations). A spatial correlation analysis shows that 12 'good' models mimic the observed inverse relationship between AZM and ISMR, although the magnitude of the simulated correlation is less (Figure 2a-b). The 6 'weak' models simulate a positive correlation which means that these models simulate an in-phase relationship between AZM and ISMR (Figure 2c).

To visualize how the pattern of rainfall anomalies over the Indian continent correlate with AZM, a spatial correlation analysis between AZM index and seasonal mean rainfall is carried out. The multimodel mean of 12 'good' models shows negative correlation values over central India and western Ghats as in observations 
(Figure 2d-e). As expected, the 'weak' models show positive correlation values over central India (Figure 2f). In summary, we find that few models in the CMIP6 archive simulate an opposite phase relationship between AZM and ISMR when compared to observations. The dynamics behind the odd behaviour of these few models will be evaluated in a separate study.

The spatial correlation pattern of AZM index and SST anomalies simulated by the selected CMIP6 models is shown in Figure 3. Observations show a peak correlation near the eastern equatorial Atlantic (Figure 3a). While the models show a similar pattern, SST anomalies are weak and more confined to the equator in the simulations compared to observations (Figure 3). There is no significant difference between 'good' and 'weak' models with regard to SST anomalies.

\section{Weakening of AZM-ISMR relationship in future global warming scenario}

In this section, we investigate the changes in the AZM-ISMR teleconnection between the present and future climate. A regression analysis is conducted between the AZM indices with the boreal summer (JJAS) rainfall anomalies (after removing ENSO influence) at every grid points over the Indian subcontinent for each period. An average (sign dependent area averaging discussed in section 2) regression value over central India represents the response of ISMR to the AZM. All the 12 'good' models show a weakening of the AZM-ISMR relationship in the future warming scenario (Figure 4a). The sign of relationship has changed from negative to positive in the future climate in 7 models (Figure 4a). The spatial pattern of the AZM-ISMR relationship shows an inverse relationship between AZM and rainfall over central India and the Western Ghats in the present climate (Figure 4b). However, the pattern changes significantly towards the end of the $21^{\text {st }}$ century with patches of positive and negative correlation coefficients (Figure 4c). In particular, north-west India shows an increase (decrease) in ISMR in response to warm 
(cold) phases of AZM in the future scenario in sharp contrast to the present climate. Besides, some parts of south-east central India and western Ghats show a decrease (increase) in seasonal rainfall in response to warm (cold) phases of AZM in a warming scenario (Figure 4c). This implies that in the future climate, the seasonal prediction of ISMR will be more challenging as the memory from the eastern equatorial Atlantic forcing weakens.

As mentioned earlier, observational studies indicate a robust AZM-ISMR relationship in recent decades due to the increase in the tropical Atlantic SST variability (e.g. Sabeerali et al, 2019). The interesting aspect coming out from the CMIP6 simulations is that the AZM-ISMR teleconnection in the future climate is not in line with the present climate and observations (Figure 4). However, the AZM variability in the future period (2050-2099) when compared with the present (1965-2014), as assessed from the 12 'good' models do not show a marked difference (Figure 5a,b). The intermodel relationship between AZM amplitude change and the changes in rainfall response over central India displays a near-zero correlation (Figure 5c). Hence, there is no evidence to attribute the changes in AZM-ISMR teleconnection to the eastern equatorial Atlantic SST variability in the SSP5-8.5 simulations. In the following sections, we explore the factors responsible for the weakening of AZM-monsoon teleconnection in the future climate.

4.1 Role of model biases to the weakening of AZM-ISMR relationship in future climate

The CMIP6 models also display biases like the CMIP5 models (e.g. Kucharski and Joshi, 2017; Richter et al, 2014) in simulating the tropical Atlantic mean SST variability and AZM-ISMR teleconnection. Most models show a warm SST bias over the eastern tropical Atlantic (figure not shown) and a weak AZM-ISMR teleconnection compared to observations (Figure 1). Although the 12 selected models capture the sign of the relationship between AZM and ISMR, the magnitude of the 
correlation varies from model to model indicating a bias. The question is whether these biases have any impact/role on the future projection of the AZM-ISMR relationship. The changes (HIST vs SSP5-8.5 simulations) in central India rainfall response and the biases in the eastern equatorial Atlantic mean SST do not show any significant relation $(\mathrm{r}=0.17$; Figure $6 \mathrm{a})$. Similarly, the changes in central India rainfall response and biases in the AZM-ISMR teleconnection also do not show any significant relationship ( $\mathrm{r}=0.08$; Figure $6 \mathrm{~b}$ ). This implies that there is no clear evidence to suggest either the SST bias over the tropical Atlantic or the bias of the AZM-ISMR teleconnection itself plays a dominant role in the future weakening of AZM-ISMR teleconnection.

4.2 Underlying mechanism driving the weak AZM-monsoon teleconnection in future climate

Previous studies discuss the detailed physical mechanism through which the AZM influences Indian summer monsoon (Kucharski et al, 2008; Pottapinjara et al, 2014; Sabeerali et al, 2018, 2019). The Gill-Matsuno type response of the atmosphere (Gill, 1980) to the eastern equatorial Atlantic SST anomalies leads to eastward propagating atmospheric Kelvin waves to the Indian Ocean and westward propagating Rossby waves to the North America and East Pacific. The atmospheric Kelvin waves reduce (enhance) the meridional gradient in upper tropospheric temperature over the monsoon domain during warm (cold) AZM phases. As a result of the meridional upper tropospheric temperature gradient changes over the monsoon domain, the large-scale winds and moisture transport to the Indian subcontinent weakens (enhances). This leads to weakening (strengthening) of the monsoon rainfall during warm (cold) AZM phases. The warm (cold) SST anomalies associated with AZM induce an enhanced (decreased) convection over the eastern tropical Atlantic region. As a response of this, an upper-level divergence (convergence) over tropical Atlantic region and a compensating upper-level convergence (divergence) 
in the tropical west/central Pacific region is evident during the warm (cold) phase of AZM (Sabeerali et al, 2019). The strength of the AZM-ISMR teleconnection depends on the strength of the tropical Atlantic convection response to the underlying SST anomalies, manifested in a maximum rising motion at around $600 \mathrm{hPa}$ (see Jia et al, 2019).

The response of tropical Atlantic convection to the underlying SST anomalies can be shown by regressing the AZM index onto atmospheric vertical velocity and flow vectors (Figure $7 \mathrm{~b}-\mathrm{c}$ ). In both the present and future climate, the response of equatorial Atlantic convection to the underlying SST anomalies shows ascending motion in the eastern tropical Atlantic and descending motion in the central/western Pacific during the positive/warm phase of AZM (Figure 7b-c). The multimodel mean of 12 'good' models shows a reduction of eastern equatorial Atlantic vertical velocity response in the future climate (Figures 7c). Further for the sake of clarity, we regressed the $600 \mathrm{hPa}$ vertical velocity (maximum vertical velocity occurs at around $600 \mathrm{hPa}$ ) onto the AZM index, and the resultant regression coefficient averaged over the eastern equatorial Atlantic Ocean is shown in Figure $7 \mathrm{a}$. The $600 \mathrm{hPa}$ vertical velocity response to AZM over the eastern equatorial Atlantic Ocean displays a weaker response in future climate in all 12 'good' models (Figure 7a).

The thermal structure of the atmosphere is of utmost importance in determining convection over a region. In the atmosphere, thermal stability refers to the ability to resist vertical motion/convection. The mean vertical thermal profile of troposphere shows a decrease in atmospheric temperature with height. In the warming scenario, the mid-troposphere warm faster than the near-surface levels due to the diabatic heating anomalies (Figure 8a) consistent with previous studies (Allen and Sherwood, 2008; Jia et al, 2019). This means that the thermal contrast between upper and lower troposphere decreases in future climate. The negative vertical temperature gradient over the eastern tropical Atlantic reduces in the SSP5-8.5 simulations (Figure 8b). Here, a negative vertical gradient is defined as 
the difference between the atmospheric temperature at $600 \mathrm{hPa}$ and $925 \mathrm{hPa}$. The term 'negative' vertical gradient is used to compensate for the decrease in atmospheric temperature with altitude. The reduction of negative vertical temperature gradient implies an increase in the atmospheric stability and its ability to resist vertical motion/convection in a warming scenario. All the 12 'good' models show a weakening of the negative vertical temperature gradient (positive values in the $\mathrm{X}$-axis of Figure 8b) in SSP5-8.5 simulations. The damping effect of increasing atmospheric stability dominates the SST changes in the eastern equatorial Atlantic in the future. As a result, the atmospheric convection over the eastern equatorial Atlantic reduces in the future climate.

The weakening of equatorial Atlantic convection influences the circulation pattern over the Indian subcontinent during boreal summer. The present climate shows an upper-level convergence over the equatorial Atlantic and an upper-level divergence over the Indian subcontinent in response to the cold phase of AZM (Figure 9a). Note that the pattern reverses in a warm AZM phase. This result is consistent with previous observational results (Kucharski et al, 2008; Sabeerali et al, 2018, 2019). The strengthening of atmospheric thermal stability over the tropical Atlantic and the associated changes in convection leads to the weakening of velocity potential response over the Indian subcontinent in a warming scenario (Figure 9b).

During boreal summer, the low-level winds are westerlies, and the upper-level winds are easterlies over the Indian subcontinent indicating a baroclinic vertical structure (e.g. Goswami and Ajayamohan, 2001). The warm (cold) phases of AZM shows an anticyclonic (cyclonic) low-level wind response over central India in HIST simulations. However, the low-level wind response weakens in the SSP5-8.5 simulations (Figure 10b), entailing the weakening of AZM-ISMR teleconnection in the future climate. The changes in ISMR response and changes in the negative vertical temperature gradient over the equatorial Atlantic correlate very well (Figure 8b). Jia et al (2019) also find a weakening of vertical velocity response 
caused by the enhanced atmospheric stability in the future climate over eastern equatorial Atlantic in CMIP5 simulations. These results give an inkling that the recent strengthening of AZM-ISMR teleconnection in the observational data is not an after-effect of greenhouse warming, but instead, it is induced by the increase in Atlantic SST variability, as shown in Sabeerali et al (2019). In other words, the changes in eastern equatorial SST variability dominates over the atmospheric thermal stability change in determining convection over there in the recent observational period. However, the increase in atmospheric thermal stability dominates the eastern equatorial SST variability in the future climate.

\section{Conclusion}

The Atlantic Zonal Mode (AZM) is a dominant mode of interannual climate variability in the tropical Atlantic Ocean that emerges from the air-sea coupled interaction similar to ENSO in the Pacific. The AZM peaks during the boreal summer season, and it impacts the global weather pattern in different ways. An inverse relationship between the ISMR and the eastern equatorial Atlantic SST variability is evident. Observational studies indicate a strengthening relationship between ISMR and AZM in recent decades due to an increased interannual SST variability in the tropical Atlantic. The enhanced AZM-ISMR relationship provides an additional parameter for predicting seasonal mean monsoon in advance. In that respect, the impact of AZM-ISMR response in a warming scenario assumes significance. Here, we study the AZM-ISMR relationship in the future climate using a suite of CMIP6 coupled model simulations.

In this study, first, we analyze the simulation of AZM-ISMR teleconnection in a suite of 23 CMIP6 coupled models. Most CMIP6 models show systematic bias in simulating the AZM-ISMR teleconnection compared to observations. Out of 23 models analyzed, only 12 models capture the correct sign of AZM-ISMR teleconnection. The rest of the models either capture an opposite teleconnection or 
no significant relationship. Here, these 12 models are used to study the AZM-ISMR

teleconnection in the future climate. All these 12 models show a weakening of AZM-

ISMR teleconnection in the SSP5-8.5 (the highest emission scenario) simulations.

Most CMIP6 models show a warm SST bias over the eastern tropical Atlantic. Although the selected 12 models capture the correct sign of the relationship between ISMR and AZM, biases in simulating the teleconnection's strength vary from model to model. Almost all models underestimate the strength of this relationship. The study finds no clear evidence to suggest either the tropical Atlantic SST bias or the bias of the AZM-ISMR teleconnection itself is responsible for the future weakening of AZM-ISMR teleconnection.

The atmospheric thermal structure has a crucial role in determining the convective responses over the eastern equatorial Atlantic. The mid-troposphere warms faster than the near-surface levels in the future climate in the selected models. It indicates an increase in the thermal stability of the atmosphere in the warming scenario. The increase in atmospheric thermal stability over the tropical Atlantic weakens the convective responses over the eastern equatorial Atlantic in response to warm phases of AZM. This lead to a reduction in the upper-level velocity potential and low-level wind response over the Indian subcontinent resulting in weak AZM-ISMR teleconnection. The changes (HIST vs SSP5-8.5) in ISMR response and atmospheric thermal stability changes over the eastern equatorial Atlantic show a strong correlation. However, there is no clear evidence to connect the changes in tropical Atlantic SST variability to the weakening of AZM-ISMR teleconnection in SSP5-8.5 scenario.

This analysis demonstrates that the damping effect of increasing atmospheric thermal stability dominates over the SST variability changes over the tropical Atlantic in a warming scenario. However, the recent strengthening of AZM-ISMR teleconnection seen in the observational data is caused by increased tropical Atlantic SST variability; not by greenhouse warming. The take-home point from this study is that, if greenhouse warming continuously increases at the current rate, 
379 the future prediction of ISMR will be more challenging as the memory from the

380 tropical Atlantic Ocean weakens.

\section{Acknowledgements}

This research is fully funded by the Center for Prototype Climate Modeling, New York University Abu Dhabi (NYUAD) through the Research Institute Grant. The authors declare no competing financial interests. All datasets used in this study are publicly available. India Meteorological Department (IMD) high reso-

386 lution gridded rainfall data $\left(0.25^{\circ} \mathrm{X} 0.25^{\circ}\right)$ are available to download from the

387 IMD Pune website (http://www.imdpune.gov.in/Clim_Pred_LRF_New/Grided_

388 Data_Download.html). The HadISST used in this study are available on https:

389 //www.metoffice.gov.uk/hadobs/hadisst/. 


\section{References}

Ajayamohan RS, Goswami BN (2000) A common spatial mode for intra-seasonal and inter-annual variation and predictability of the Indian summer monsoon. Current Science 79(8):1106-1111, http://repository.ias.ac.in/93641/

Allen RJ, Sherwood SC (2008) Warming maximum in the tropical upper troposphere deduced from thermal winds. Nature Geoscience 1(6):399-403

Ashok K, Guan Z, Yamagata T (2001) Impact of the Indian ocean dipole on the relationship between the Indian monsoon rainfall and ENSO. Geophys Res Lett 28(23):4499-4502, DOI 10.1029/2001GL013294

Azad S, Rajeevan M (2016) Possible shift in the ENSO-Indian monsoon rainfall relationship under future global warming. Sci Rep 6:20,145, DOI 10.1038/ srep20145

Bjerknes J (1969) Atmospheric teleconnections from the equatorial Pacific. Mon Weather Rev 97(3):163-172

Carton JA, Huang B (1994) Warm events in the tropical Atlantic. J Phys Oceanogr 24(5):888-903, DOI 10.1175/1520-0485(1994)024〈0888:WEITTA $\rangle 2.0 . C O ; 2$

Chang CY, Carton JA, Grodsky SA, Nigam S (2007) Seasonal climate of the tropical Atlantic sector in the NCAR community climate system model 3: Error structure and probable causes of errors. J Climate 20(6):1053-1070, DOI 10. 1175/JCLI4047.1

Chattopadhyay R, Phani R, Sabeerali CT, Dhakate AR, Salunke KD, Mahapatra S, Rao AS, Goswami BN (2015) Influence of extratropical sea-surface temperature on the Indian summer monsoon: an unexplored source of seasonal predictability. Quart J Roy Meteorol Soc 141(692):2760-2775, DOI 10.1002/qj.2562 Ding H, Keenlyside NS, Latif M (2010) Equatorial Atlantic interannual variability: Role of heat content. J Geophys Res 115(C9):C09,020, DOI 10.1029/ 2010JC006304

Ding H, Keenlyside NS, Latif M (2012) Impact of the equatorial Atlantic on the El Niño southern oscillation. Clim Dynam 38(9-10):1965-1972, DOI 10.1007/ 
s00382-011-1097-y

Ding H, Greatbatch RJ, Latif M, Park W (2015a) The impact of sea surface temperature bias on equatorial Atlantic interannual variability in partially coupled model experiments. Geophys Res Lett 42(13):5540-5546, DOI 10.1002/2015GL064799

Ding H, Keenlyside N, Latif M, Park W, Wahl S (2015b) The impact of mean state errors on equatorial Atlantic interannual variability in a climate model. J Geophys Res 120(2):1133-1151, DOI 10.1002/2014JC010384

Eyring V, Bony S, Meehl GA, Senior CA, Stevens B, Stouffer RJ, Taylor KE (2016) Overview of the Coupled Model Intercomparison Project Phase 6 (CMIP6) experimental design and organization. Geosci Model Dev 9:1937-1958, DOI 10.5194/gmd-9-1937-2016

Foltz GR, McPhaden MJ (2010) Interaction between the Atlantic meridional and niño modes. Geophys Res Lett 37(18), DOI 10.1029/2010GL044001

Gadgil S, Gadgil S (2006) The indian monsoon, gdp and agriculture. Economic and Political Weekly 41(47):4887-4895, DOI 10.2307/4418949, available at http://www.jstor.org/stable/4418949

Gill AE (1980) Some simple solutions for heat-induced tropical circulation. Quart J Roy Meteorol Soc 106:447-462

Goswami BN, Ajayamohan RS (2001) Intraseasonal oscillations and interannual variability of the Indian summer monsoon. J Climate 14:1180-1198, DOI 10. 1175/1520-0442(2001)014〈1180:IOAIVO $\rangle 2.0 . \mathrm{CO} ; 2$

Ham YG, Kug JS, Park JY, Jin FF (2013) Sea surface temperature in the north tropical Atlantic as a trigger for El Niño/Southern oscillation events. Nature Geosci 6(2):112-116, DOI 10.1038/ngeo1686

Jansen MF, Dommenget D, Keenlyside N (2009) Tropical atmosphere-ocean interactions in a conceptual framework. J Climate 22(3):550-567, DOI 10.1175/ 2008JCLI2243.1 
Jia F, Cai W, Wu L, Gan B, Wang G, Kucharski F, Chang P, Keenlyside N (2019) Weakening Atlantic Niño-Pacific connection under greenhouse warming. Sci Adv 5(8):eaax4111, DOI 10.1126/sciadv.aax4111

Keenlyside NS, Latif M (2007) Understanding equatorial Atlantic interannual variability. J Climate 20(1):131-142, DOI 10.1175/JCLI3992.1

Keenlyside NS, Ding H, Latif M (2013) Potential of equatorial Atlantic variability to enhance El Niño prediction. Geophys Res Lett 40(10):2278-2283, DOI 10. $1002 / \operatorname{grl} .50362$

Krishnamurthy V, Shukla J (2007) Intraseasonal and seasonally persisting patterns of Indian monsoon. J Climate 20:3-20, DOI 10.1175/JCLI3981.1

Kucharski F, Joshi MK (2017) Influence of tropical south Atlantic sea-surface temperatures on the Indian summer monsoon in CMIP5 models. Quart J Roy Meteorol Soc 143(704):1351-1363, DOI 10.1002/qj.3009

Kucharski F, Bracco A, Yoo J, Molteni F (2008) Atlantic forced component of the Indian monsoon interannual variability. Geophys Res Lett 35(4), DOI 10.1029/ 2007GL033037

Li X, Ting M (2015) Recent and future changes in the Asian monsoon-ENSO relationship: Natural or forced? Geophys Res Lett 42(9):3502-3512, DOI 10. 1002/2015GL063557

Losada T, Rodríguez-Fonseca B, Polo I, Janicot S, Gervois S, Chauvin F, Ruti P (2010) Tropical response to the Atlantic Equatorial mode: AGCM multimodel approach. Clim Dynam 35(1):45-52, DOI 10.1007/s00382-009-0624-6

Lübbecke JF, Böning CW, Keenlyside NS, Xie SP (2010) On the connection between Benguela and equatorial Atlantic Niños and the role of the south Atlantic anticyclone. J Geophys Res 115(C9):C09,015, DOI 10.1029/2009JC005964

O’Neill BC, Claudia T, Detlef PvV, Veronika E, Pierre F, George H, Reto K, Elmar K, Jean-Francois L, Jason L, Gerald A M, Richard M, Keywan R, Benjamin M S (2016) The Scenario Model Intercomparison Project (ScenarioMIP) for CMIP6. Geosci Model Dev 9:3461-3482, DOI 10.5194/gmd-9-3461-2016 
O’Neill BC, Kriegler E, Ebi KL, Kemp-Benedict E, Riahi K, Rothman DS, van Ruijven BJ, van Vuuren DP, Birkmann J, Kok K, et al (2017) The roads ahead: Narratives for shared socioeconomic pathways describing world futures in the 21st century. Global Environmental Change 42:169-180, DOI 10.1016/j.gloenvcha.2015.01.004

Pai DS, Sridhar L, Rajeevan M, Sreejith OP, Satbhai N, Mukhopadhyay B (2014) Development of a new high spatial resolution $(0.25 \times 0.25)$ long period $(1901-$ 2010) daily gridded rainfall data set over India and its comparison with existing data sets over the region. Mausam 65(1):1-18

Philander SG (1990) El Niño, La Niña, and the Southern Oscillation. International Geophysics Series, vol 46, Academic Press, pp 1-293, DOI 10.1016/ S0074-6142(13)60002-9

Pottapinjara V, Girishkumar MS, Ravichandran M, Murtugudde R (2014) Influence of the Atlantic zonal mode on monsoon depressions in the Bay of Bengal during boreal summer. J Geophys Res 119(11):6456-6469, DOI 10.1002/ 2014JD021494

Pottapinjara V, Girishkumar MS, Sivareddy S, Ravichandran M, Murtugudde R (2016) Relation between the upper ocean heat content in the equatorial Atlantic during boreal spring and the Indian monsoon rainfall during June-September. Int J Climatol 36(6):2469-2480, DOI 10.1002/joc.4506

Rasmusson EM, Wallace JM (1983) Meteorological aspects of the El Niño/Southern Oscillation. Science 222:1195-1202, DOI 10.1126/science.222. 4629.1195

Rayner NA, Parker DE, Horton EB, Folland CK, Alexander LV, Rowell DP, Kent EC, Kaplan A (2003) Global analyses of sea surface temperature, sea ice, and night marine air temperature since the late nineteenth century. J Geophys Res 108(D14):4407, DOI 10.1029/2002JD002670

Richter I, Xie SP (2008) On the origin of equatorial Atlantic biases in coupled general circulation models. Clim Dynam 31(5):587-598, DOI 10.1007/ 
s00382-008-0364-z

Richter I, Xie SP, Behera SK, Doi T, Masumoto Y (2014) Equatorial Atlantic variability and its relation to mean state biases in CMIP5. Clim Dynam 42(12):171-188, DOI 10.1007/s00382-012-1624-5

Rodríguez-Fonseca B, Polo I, García-Serrano J, Losada T, Mohino E, Mechoso CR, Kucharski F (2009) Are Atlantic Niños enhancing Pacific ENSO events in recent decades? Geophys Res Lett 36(20), DOI 10.1029/2009GL040048

Roy I, Tedeschi RG, Collins M (2019) ENSO teleconnections to the Indian summer monsoon under changing climate. Int J Climatol 39(6):3031-3042, DOI 10.1002/ joc.5999

Sabeerali CT, Ajayamohan RS, Rao SA (2018) Loss of predictive skill of Indian summer monsoon rainfall in NCEP CFSv2 due to misrepresentation of Atlantic zonal mode. Clim Dynam pp 1-21, DOI 10.1007/s00382-018-4390-1

Sabeerali CT, Ajayamohan RS, Bangalath HK, Chen N (2019) Atlantic zonal mode: An emerging source of Indian summer monsoon variability in a warming world. Geophys Res Lett 46(8):4460-4467, DOI 10.1029/2019GL082379

Saji NH, Goswami BN, Vinayachandran P, Yamagata T (1999) A dipole mode in the tropical Indian ocean. Nature 401:360-363, DOI 10.1038/43854

Shukla J (1987) Interannual variability of monsoon. In: Fein JS, Stephens PL (eds) Monsoons, Wiley and Sons, New York, pp 399-464

Stockdale TN, Balmaseda MA, Vidard A (2006) Tropical Atlantic SST prediction with coupled ocean-atmosphere GCMs. J Climate 19(23):6047-6061, DOI 10. 1175/JCLI3947.1

Tozuka T, Doi T, Miyasaka T, Keenlyside N, Yamagata T (2011) Key factors in simulating the equatorial Atlantic zonal sea surface temperature gradient in a coupled general circulation model. J Geophys Res 116(C6), DOI 10.1029/ 2010JC006717

Wahl S, Latif M, Park W, Keenlyside N (2011) On the tropical Atlantic sst warm bias in the kiel climate model. Clim Dynam 36(5-6):891-906, DOI 10.1007/ 
s00382-009-0690-9

Wang C, Kucharski F, Barimalala R, Bracco A (2009) Teleconnections of the tropical Atlantic to the tropical indian and pacific oceans: A review of recent findings. Meteorologische Zeitschrift 18(4):445-454, DOI 10.1127/0941-2948/2009/0394

Wang C, Zhang L, Lee SK, Wu L, Mechoso CR (2014) A global perspective on CMIP5 climate model biases. Nature Clim Change 4(3):201-205, DOI 10.1007/ s00382-009-0690-9 Yang Y, Xie SP, Wu L, Kosaka Y, Li J (2018) ENSO forced and local variability of north tropical Atlantic SST: model simulations and biases. Clim Dynam 51(1112):4511-4524, DOI 10.1007/s00382-017-3679-9

${ }_{544}$ Yeh SW, Cai W, Min SK, McPhaden MJ, Dommenget D, Dewitte B, Collins M, Ashok K, An SI, Yim BY, et al (2018) ENSO atmospheric teleconnections and their response to greenhouse gas forcing. Rev Geophys 56(1):185-206, DOI 10.1002/2017RG000568 Zebiak SE (1993) Air-sea interaction in the equatorial Atlantic region. J Climate 6(8):1567-1586, DOI 10.1175/1520-0442(1993)006〈1567:AIITEA $\rangle 2.0 . C O ; 2$ Zheng XT, Xie SP, Du Y, Liu L, Huang G, Liu Q (2013) Indian ocean dipole response to global warming in the CMIP5 multimodel ensemble. J Climate 26(16):6067-6080, DOI 10.1175/JCLI-D-12-00638.1 
Table 1: Details of CMIP6 models used in this study.

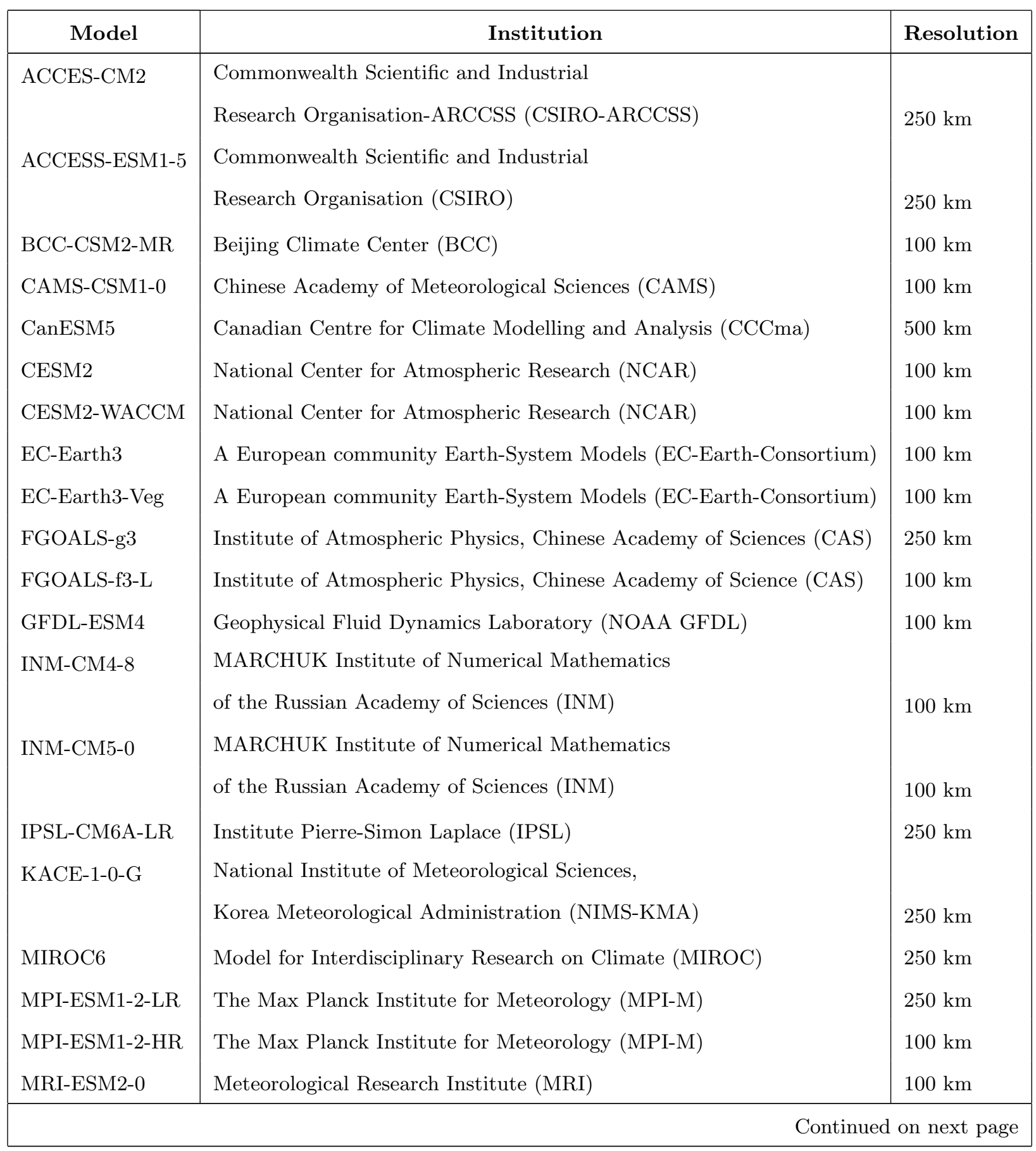


Table 1 - continued from previous page

\begin{tabular}{|l|l|l|}
\hline \multicolumn{1}{|c|}{ Model } & \multicolumn{1}{|c|}{ Institution } & Resolution \\
\hline NESM3 & Nanjing University of Information Science and Technology (NUIST) & $250 \mathrm{~km}$ \\
NorESM2-LM & Norwegian Climate Centre (NCC) & $250 \mathrm{~km}$ \\
NorESM2-MM & Norwegian Climate Centre (NCC) & $100 \mathrm{~km}$ \\
\hline
\end{tabular}




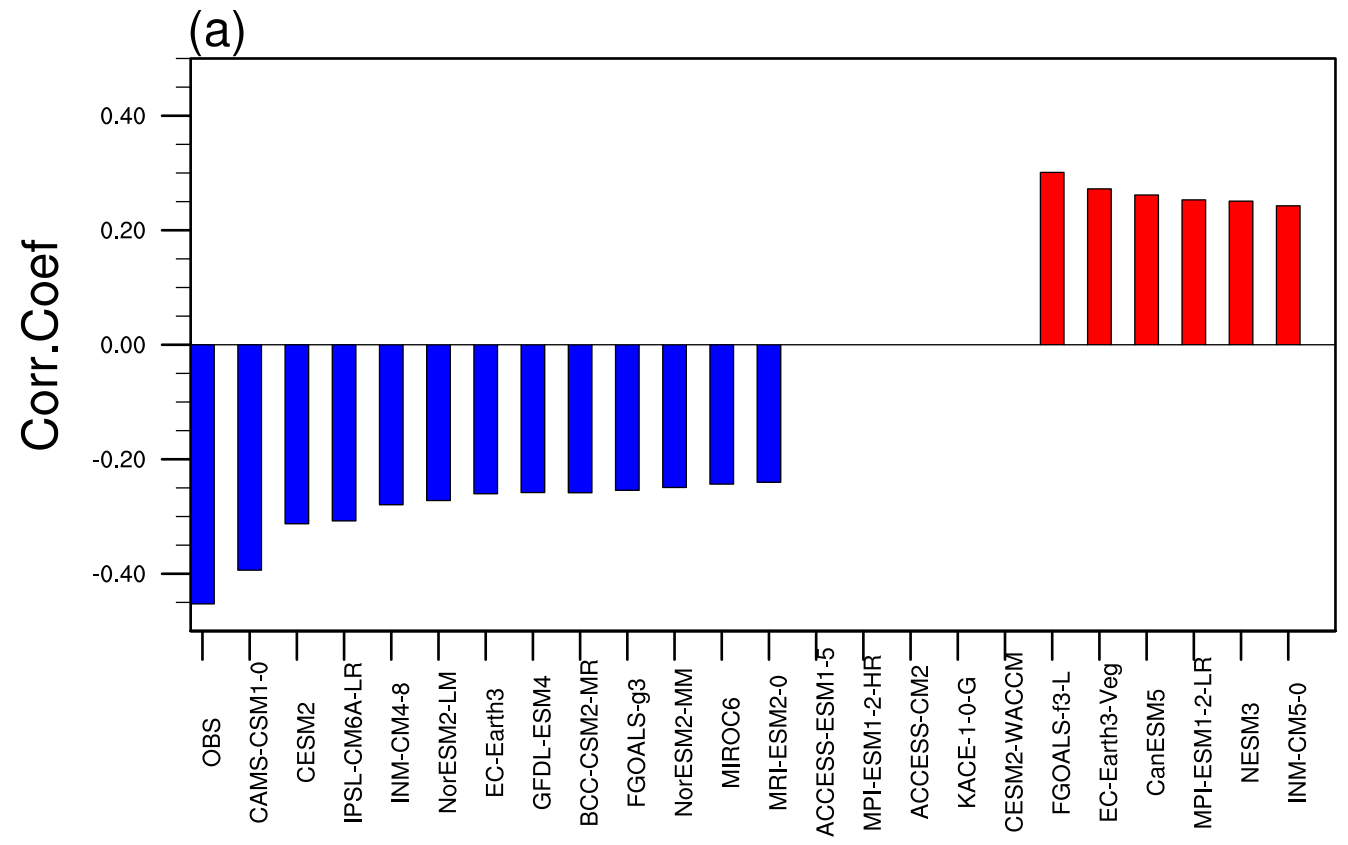

Fig. 1: AZM-ISMR teleconnection in the historical simulations (1965-2014) of CMIP6 coupled models. Bars indicate the area-average (sign dependent area averaging discussed in section 2) of statistically significant correlation value in observations and CMIP6 models. Correlation analysis is carried out between boreal summer central India rainfall anomalies (average of rainfall anomalies over the core monsoon domain $\left(18^{\circ} \mathrm{N}-28^{\circ} \mathrm{N}, 65^{\circ} \mathrm{E}-88^{\circ} \mathrm{E}\right)$ ) and $\mathrm{SST}$ anomalies (after removing ENSO influence) at all grid points over the tropical Atlantic $\left(5^{\circ} \mathrm{S}-3^{\circ} \mathrm{N}, 20^{\circ} \mathrm{W}\right.$ $10^{\circ} \mathrm{E}$ ). Models that fail to produce any significant correlations are set to be zero. The blue bars represent models that simulate the correct sign of AZM-ISMR teleconnection when compared to observations. Red bars denote models that simulate opposite teleconnection. 

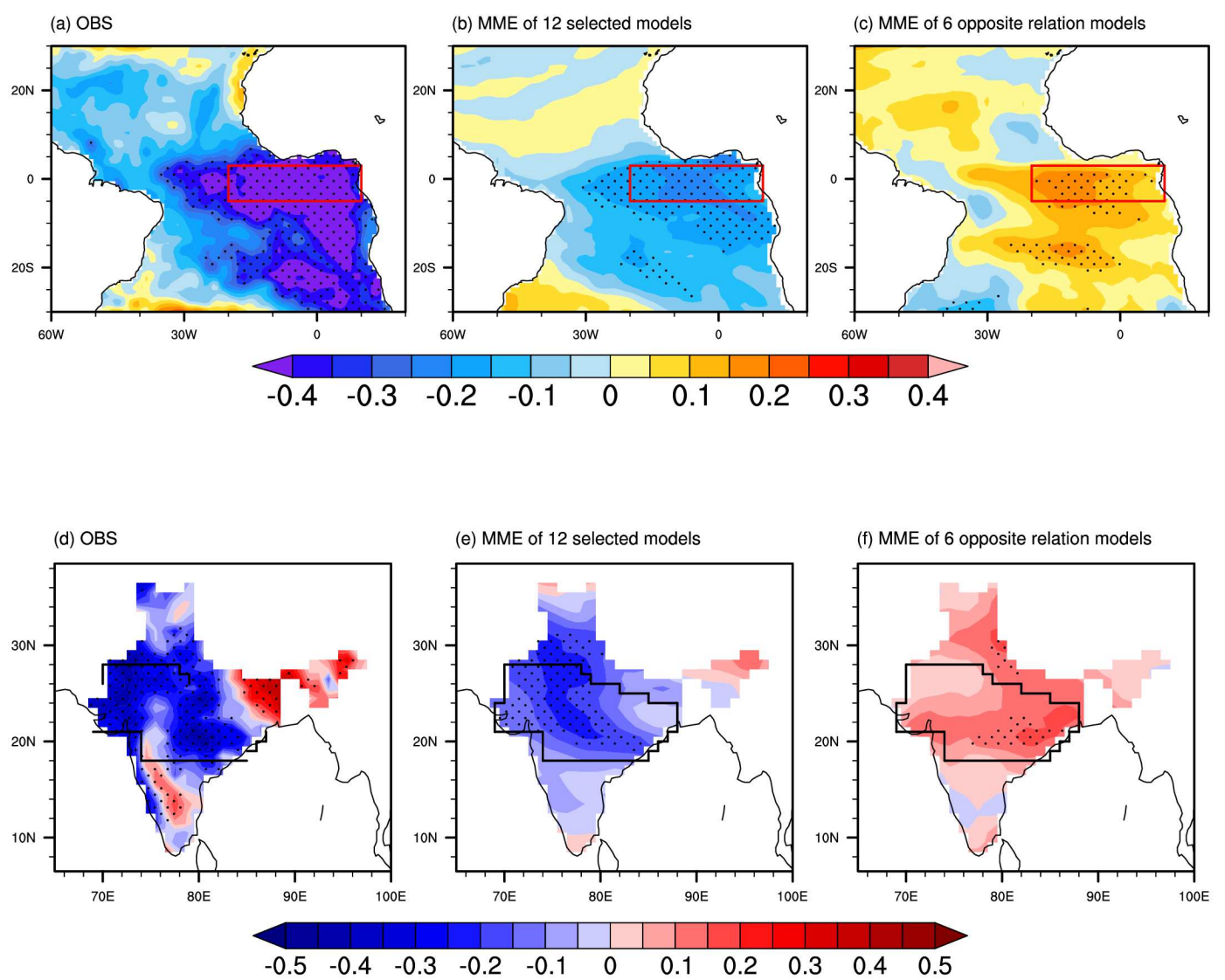

Fig. 2: The multimodel mean of AZM-ISMR teleconnection in the historical simulations (1965-2014) of CMIP6 coupled models. Spatial correlation between the boreal summer central India rainfall anomalies (average of rainfall anomalies over the core monsoon domain) and the SST anomalies (after removing ENSO influence) over the tropical Atlantic. (a) Observations (b) multi-model mean of 12 'good' models (c) multi-model mean of six 'weak' models. (d)-(f) is the same as (a)-(c), but represents the spatial map of correlation between the AZM index and the rainfall anomalies. In observations (panel (a) and (d)) correlation values greater than $95 \%$ confidence levels are stippled. Stippling in panel (b), (c), (e), and (f) denotes that the multimodel mean exceeds 1 standard deviation. 


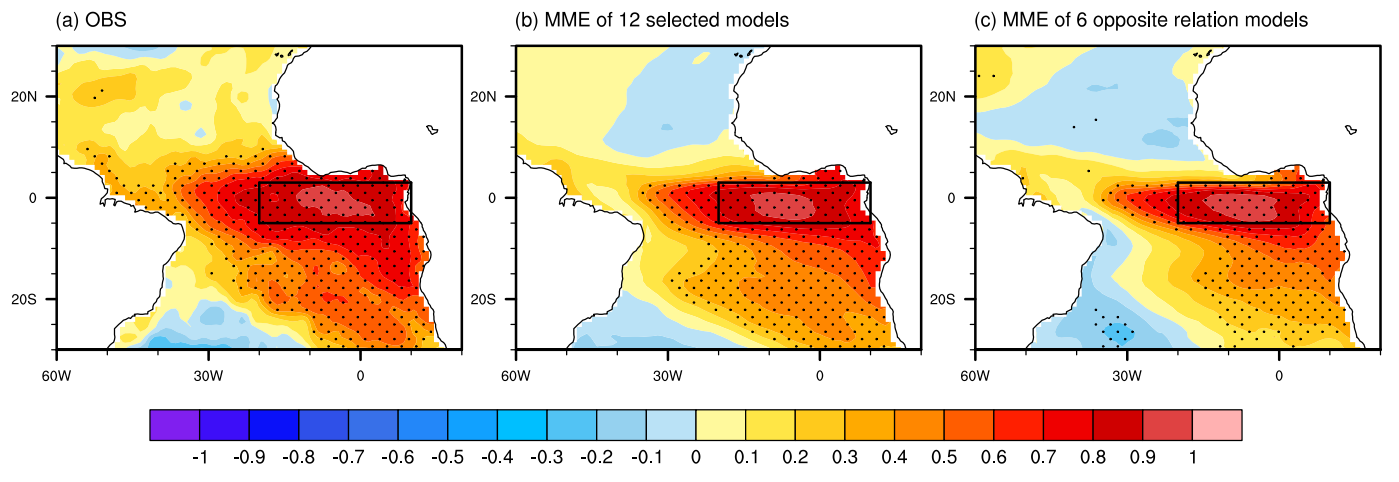

Fig. 3: Spatial correlation between the AZM index and the boreal summer (JJA) SST anomalies over the tropical Atlantic (a) Observations (b) multi-model mean of 12 'good' models (c) multimodel mean of 6 'weak' models. Correlation values greater than $95 \%$ confidence levels are stippled in panel (a). In (b) and (c) stippling denotes that the multimodel mean exceeds 1 standard deviation. 
(a) Projected weakening of AZM-ISMR relationship

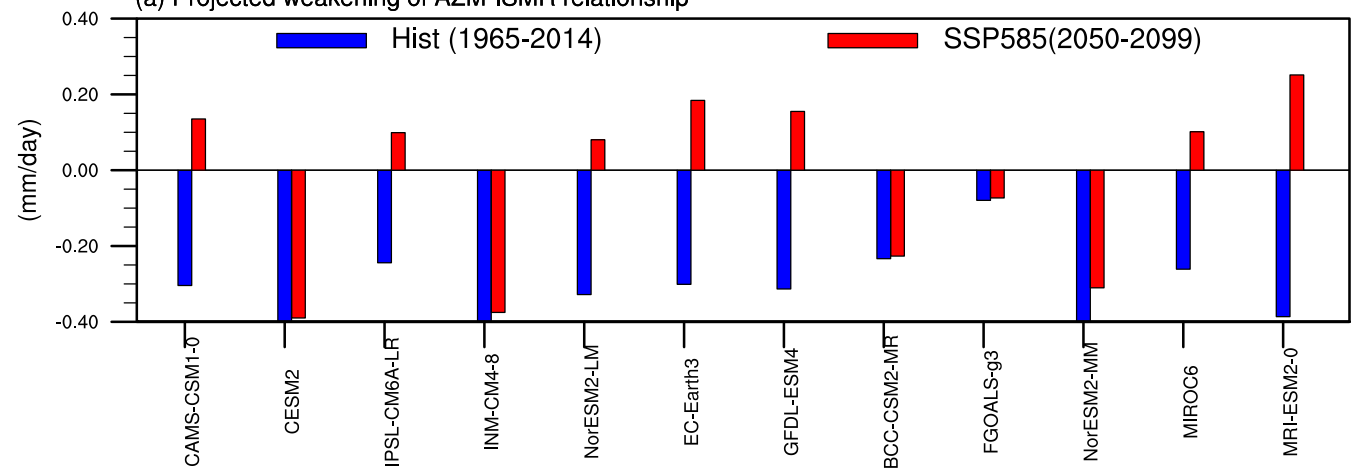

(b) Hist (1965-2014)

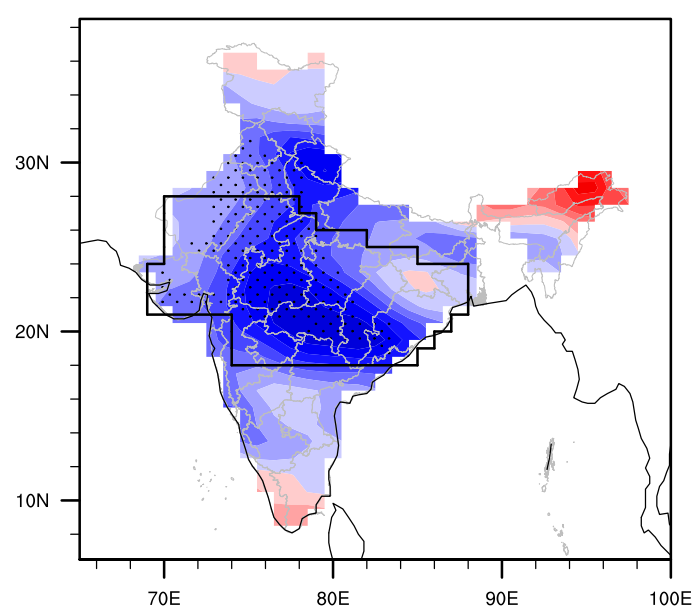

(c) SSP585 (2050-2099)

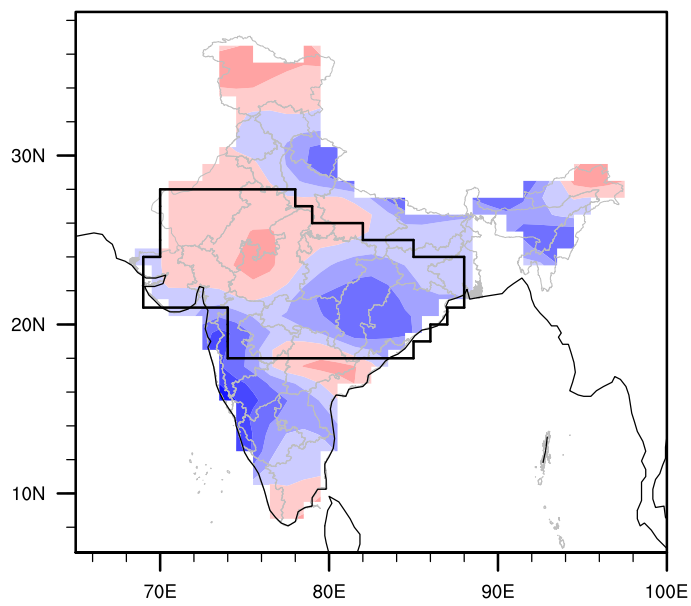

Fig. 4: The weakening of AZM-ISMR relationship in a warming scenario. Comparison of central Indian rainfall anomalies due to AZM (ENSO free component of rainfall anomalies) over the historical (blue bars; 1965-2014) and future (red bars; 2050-2099) in the 12 'good' model simulations. The multimodel mean of the regression coefficients over the Indian subcontinent in (b) historical and (c) future simulations. Stippling in (b) and (c) denotes that the multimodel mean exceeds 1 standard deviation. The regression analysis is carried out between the AZM index and the boreal summer rainfall anomalies (after removing ENSO influence). 
(c)
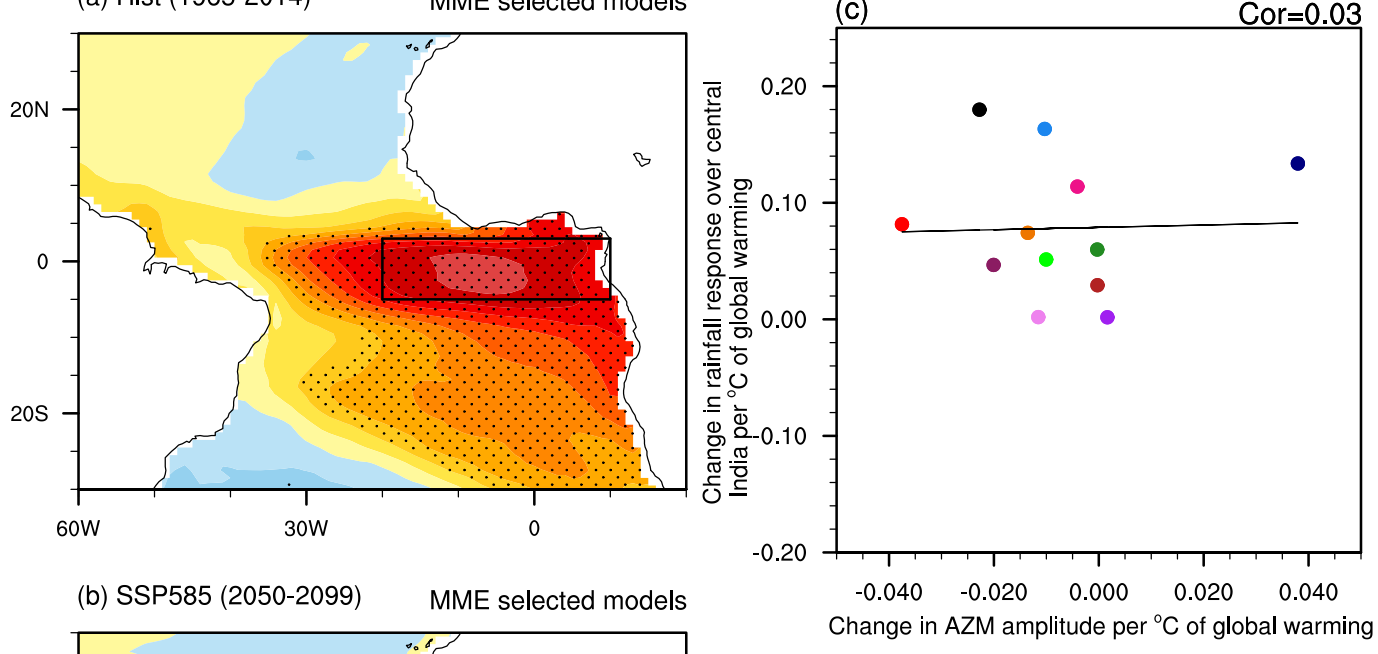

(b) SSP585 (2050-2099)

MME selected models

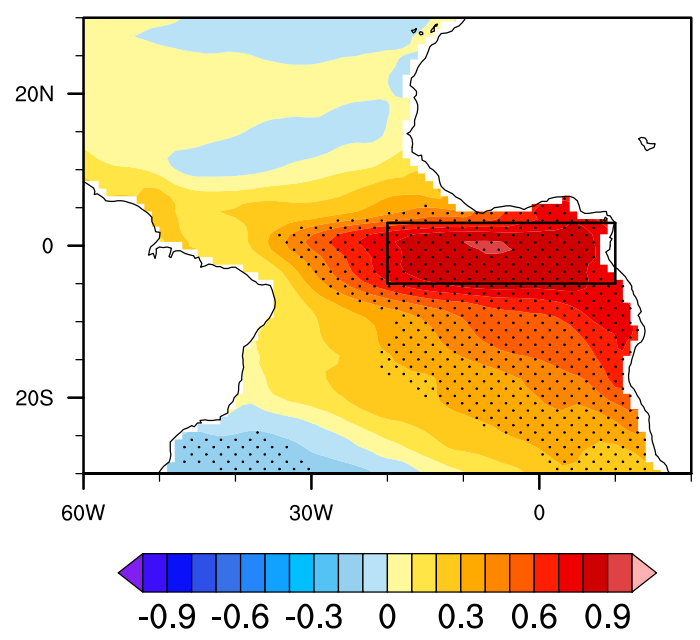

Fig. 5: Impact of AZM amplitude change on the rainfall response over India from the selected 12 CMIP6 models. Spatial correlation between the AZM index and JJA SST anomalies (a) historical (b) SSP5-8.5 simulations. Stippling in (a) and (b) denotes that the multimodel mean exceeds 1 standard deviation. (c) Intermodel relationship between AZM amplitude change (futurehistorical; X-Axis) and the changes in rainfall response over central India (future-historical; Y-axis). The black solid line represent the linear trend line. The correlation coefficient between changes in AZM amplitude and the changes in rainfall response over central India is also given in the top right corner. For a better comparison, the changes are scaled by the increase in global-mean temperature over the historical and future period. The AZM amplitude is computed by area-averaging the regressed SST anomalies (onto AZM index) in the eastern equatorial Atlantic $\left(5^{\circ} \mathrm{S}-3^{\circ} \mathrm{N}, 20^{\circ} \mathrm{W}\right.$ $10^{\circ} \mathrm{E}$ ). Similarly, the rainfall response over central India is obtained by area-averaging the regressed rainfall anomalies (onto AZM index). 

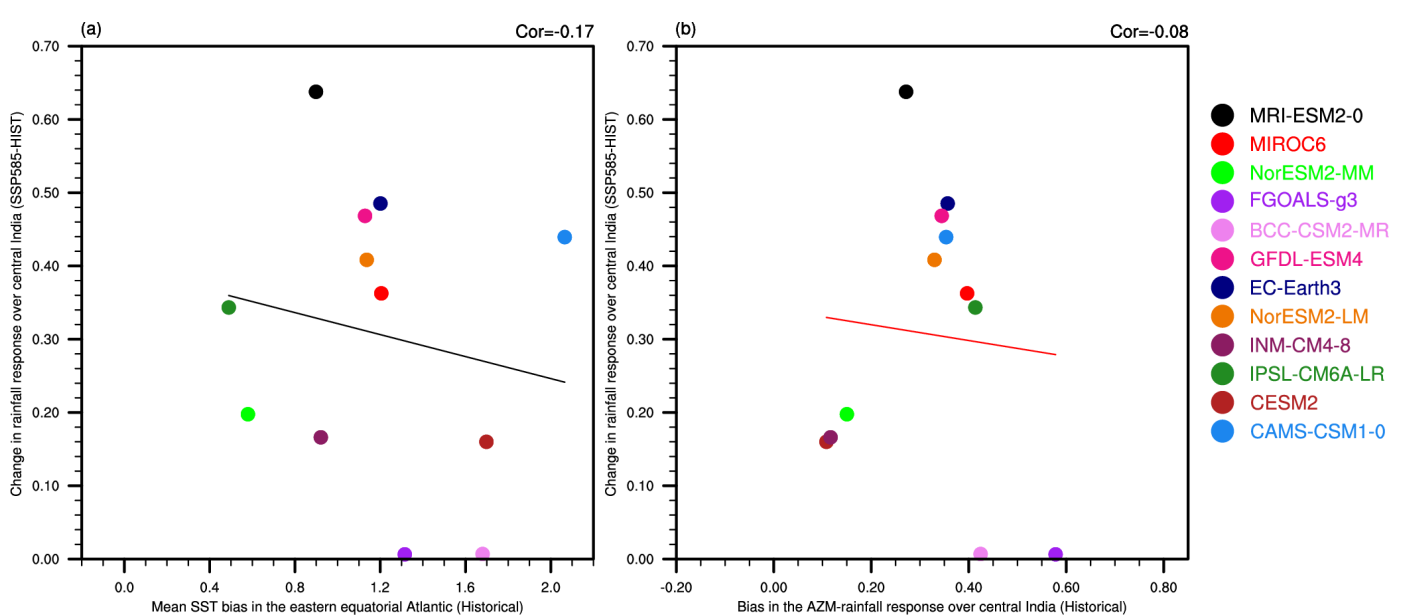

Fig. 6: Impact of model biases on the projection of rainfall responses over India. Intermodel relationship between the (a) mean $\operatorname{SST}\left({ }^{0} C\right)$ bias in the eastern equatorial Atlantic $\left(5^{\circ} \mathrm{S}-3^{\circ} \mathrm{N}\right.$, $20^{\circ} \mathrm{W}-10^{\circ} \mathrm{E}$ ) and the changes (future-historical) in rainfall $(\mathrm{mm} /$ day) response over central India (b) biases in simulating AZM-ISMR teleconnection and the changes (future-historical) in rainfall response over central India. The rainfall response over central India is obtained by area-averaging the regressed rainfall anomalies onto AZM indices. The mean Atlantic SST bias in each model is obtained by the difference of climatological mean SST over the eastern equatorial Atlantic during the historical period between model and observations. Similarly, the biases in simulating AZM-ISMR teleconnection are obtained by taking the difference of rainfall response over central India during the historical period between model and observations. The solid lines in (a) and (b) represents the trend line and correlation coefficients are denoted in the top right corner of each panel. 

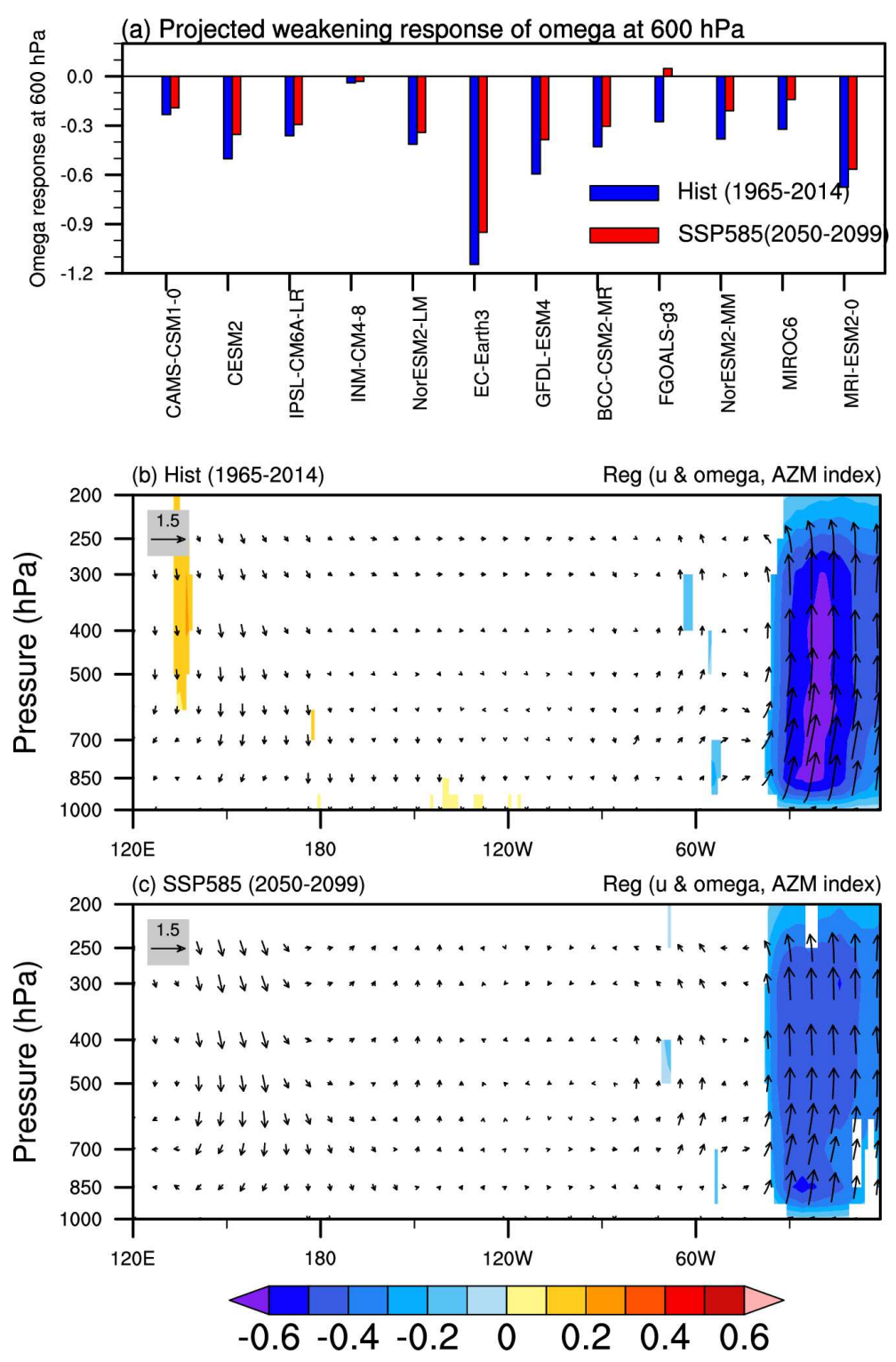

Fig. 7: Future weakening of the convective response to the AZM over the eastern equatorial Atlantic. (a) The $600 \mathrm{hPa}$ vertical velocity $\left(\mathrm{Pa} \mathrm{S}^{-1}\right)$ response to the AZM averaged over the eastern equatorial Atlantic $\left(5^{\circ} \mathrm{S}-3^{\circ} \mathrm{N}, 20^{\circ} \mathrm{W}-10^{\circ} \mathrm{E}\right)$ in historical (blue bars) and future (red bars) simulations. Multimodel mean of the regression coefficients of the equatorial $\left(5^{\circ} \mathrm{S}-5^{\circ} \mathrm{N}\right)$ atmospheric vertical velocity and the flow vectors $\left(\mathrm{ms}^{-1}\right)$ onto the AZM index in (b) historical (c) future period. Shading represents multi-model mean exceeding 1 standard deviation in (b) and (c). 

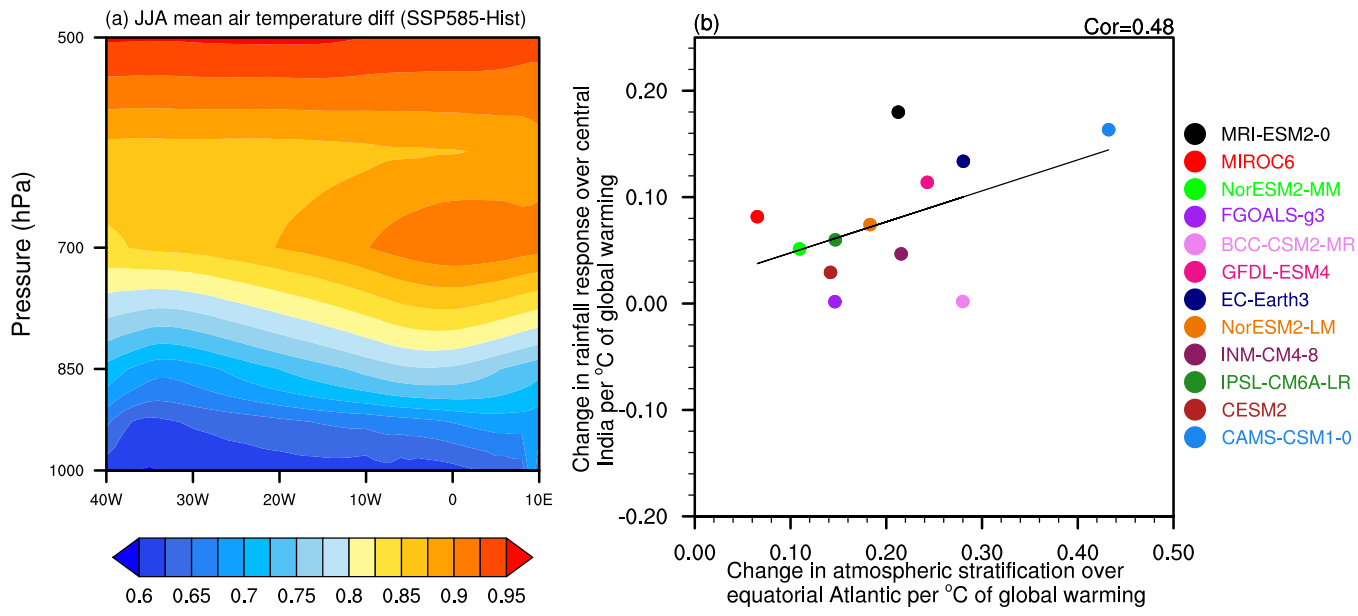

Fig. 8: Impact of increased atmospheric thermal stability on the projected weakening of AZM-ISMR relationship in future. The difference of JJA mean air temperature $\left({ }^{0} C\right)$ between the future and historical period (SSP5-8.5-historical) over the equatorial Atlantic (averaged over $\left.5^{\circ} \mathrm{S}-5^{\circ} \mathrm{N}\right)$. Intermodel relationship between the changes (future-historical) in boreal summer atmospheric stratification (X-Axis; units: ${ }^{0} C /{ }^{0} C$ ) and the rainfall response over central India (Yaxis; units: $\left.m m d a y^{-1} /{ }^{0} C\right)$. The black solid line represent the linear trend line. The atmospheric stratification is defined as the difference between the atmospheric temperature at $600 \mathrm{hPa}$ and 925 $\mathrm{hPa}$ averaged over the eastern equatorial Atlantic. The changes in both panels are scaled by the increase in global-mean temperature. 

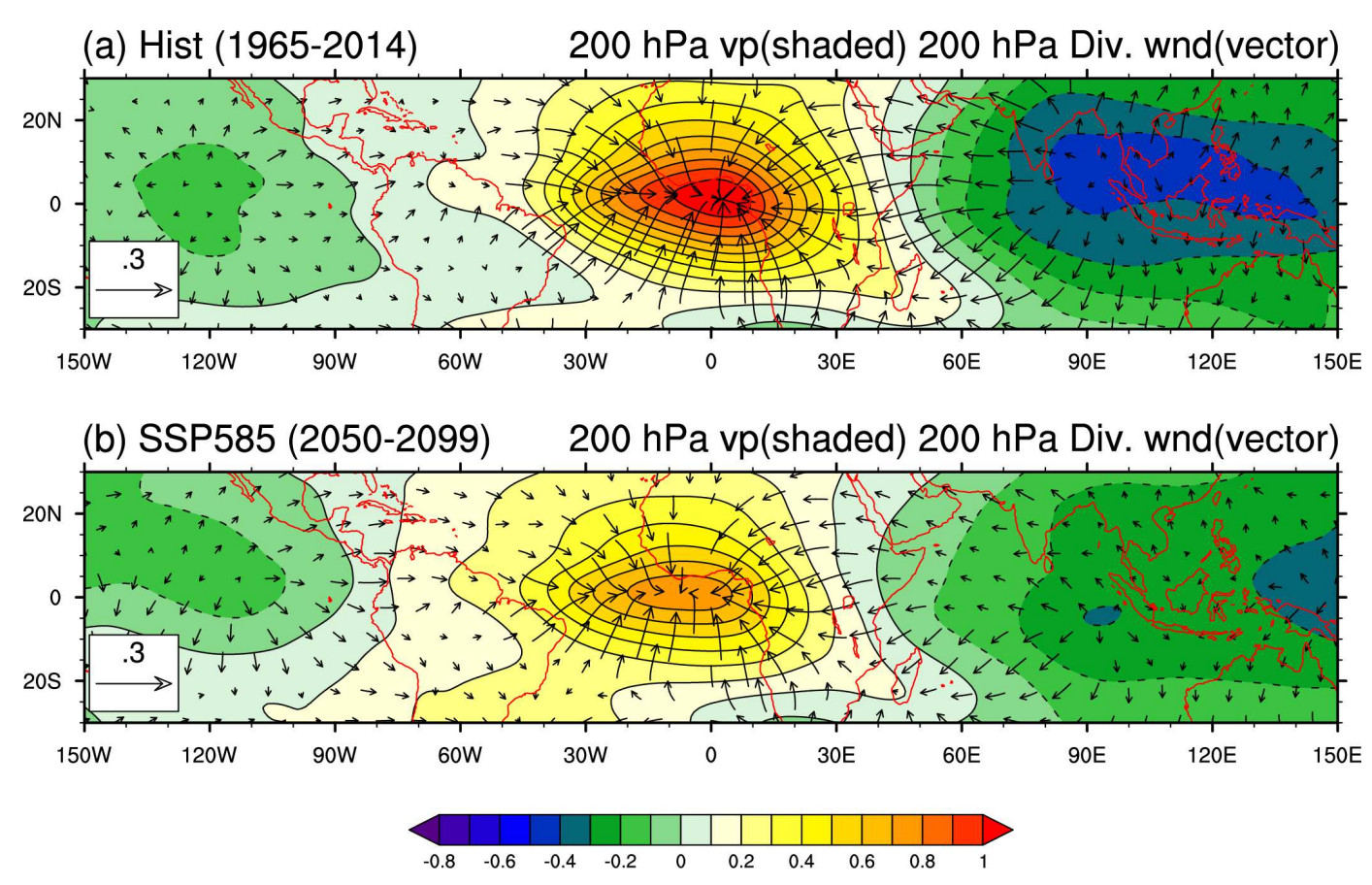

Fig. 9: The weakening of velocity potential response over India in the warming scenario. The multimodel mean of the regression coefficients of $200 \mathrm{hPa}$ velocity potential (contour) and divergent wind (vector) in (a) historical (b) SSP5-8.5 simulations. Negative (positive) contour indicates the upper-level divergence (convergence). Shading represents multimodel means above 1 standard deviation. The regression analysis is carried out between the parameters $(200 \mathrm{hPa}$ velocity potential and divergent winds) and the AZM index (multiplied by -1 ; units: $10^{6} \mathrm{~m}^{2} \mathrm{~s}^{-1}$ per standard deviation of the regression index). 
(a) Hist (1965-2014)

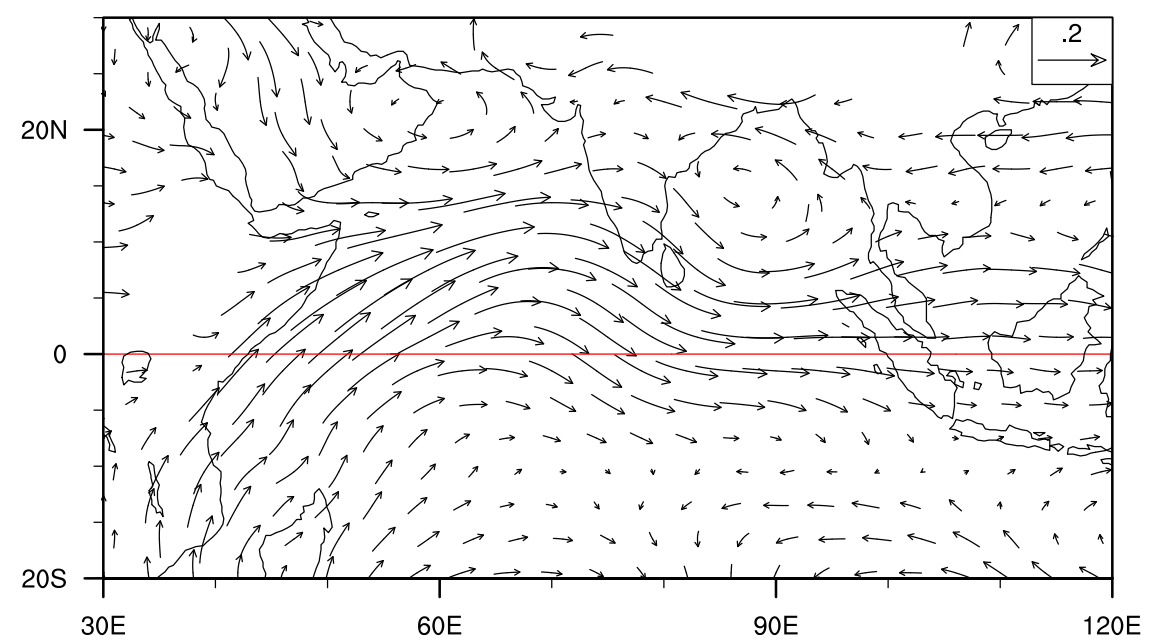

(b) SSP585 (2050-2099)

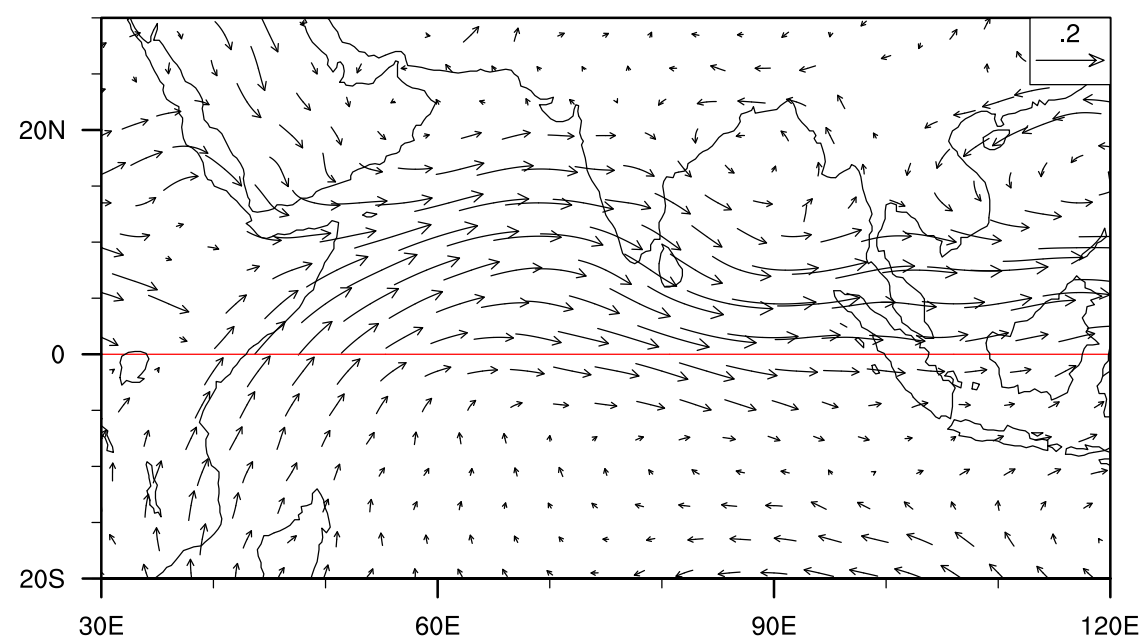

Fig. 10: The weakening of low-level wind response over central India in the warming scenario. The multimodel mean of the regression coefficients of mean low-level $(850 \mathrm{hPa})$ wind anomalies in (a) historical and (b) SSP5-8.5 simulations. The regression analysis is carried out between $850 \mathrm{hPa}$ wind anomalies and the AZM index (multiplied by -1 ; units: $\mathrm{ms}^{-1}$ per standard deviation of the regression index). 


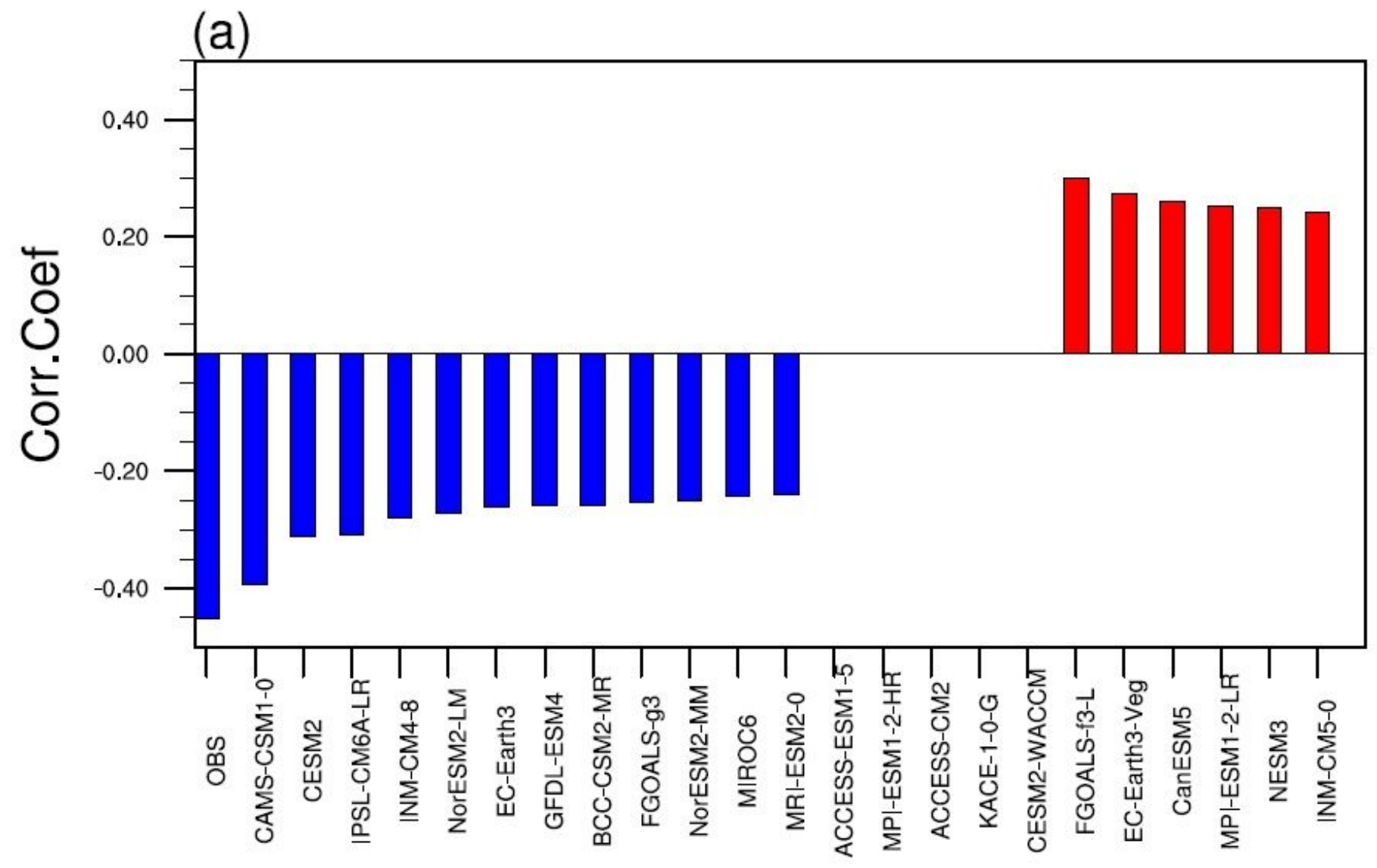

Figure 1

AZM-ISMR teleconnection in the historical simulations (1965-2014) of CMIP6 coupled models. Bars indicate the area-average (sign dependent area averaging discussed in section 2) of statistically signicant correlation value in observations and CMIP6 models. Correlation analysis is carried out between boreal summer central India rainfall anomalies (average of rainfall anomalies over the core monsoon domain $(180 \mathrm{oN}-28 \mathrm{oN}, 65 \mathrm{oE}-88 \mathrm{oE})$ ) and SST anomalies (after removing ENSO influence) at all grid points over the tropical Atlantic $(50 S-30 N, 20 \mathrm{oW}-10 \mathrm{oE})$. Models that fail to produce any signicant correlations are set to be zero. The blue bars represent models that simulate the correct sign of AZM-ISMR teleconnection when compared to observations. Red bars denote models that simulate opposite teleconnection. 
(a) OBS

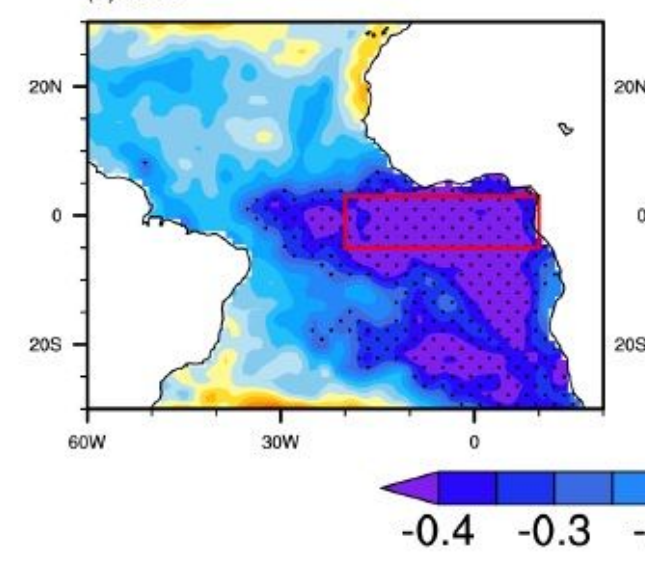

(b) MME of 12 selected models

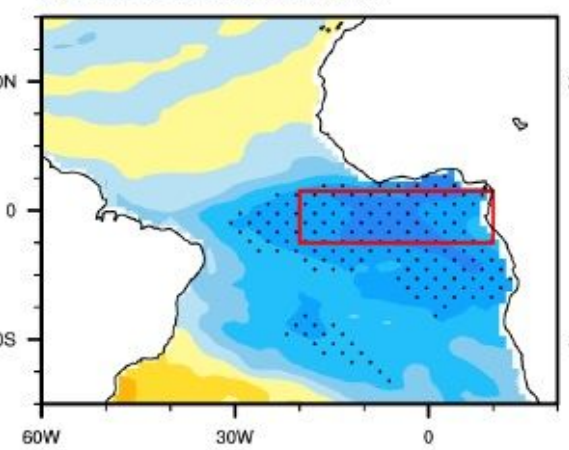

(c) MME of 6 opposite relation models

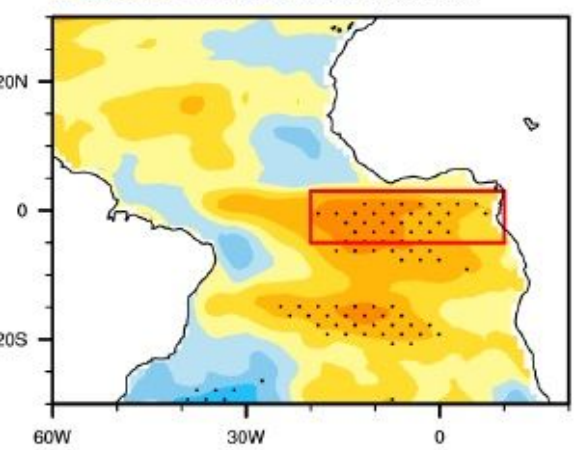

(d) OBS

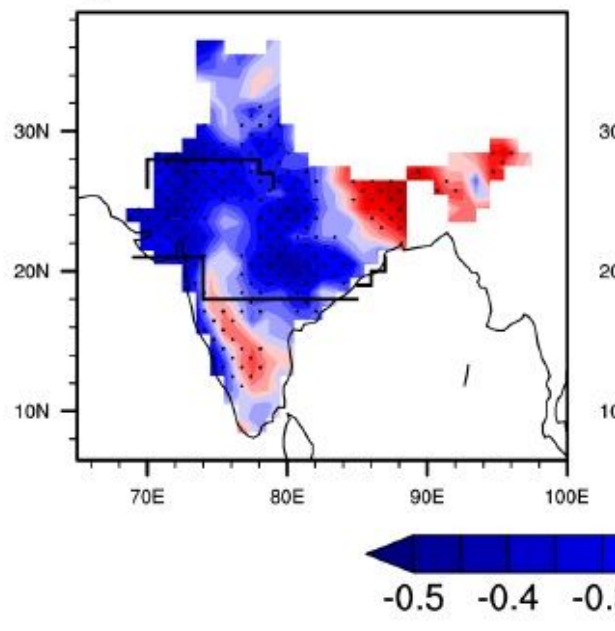

(e) MME of 12 selected models

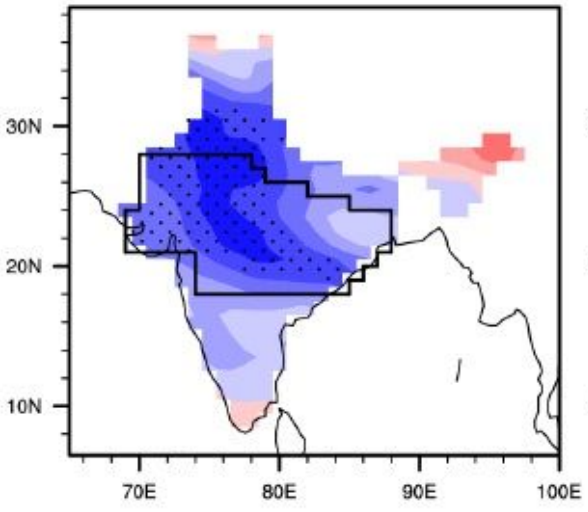

(f) MME of 6 opposite relation models

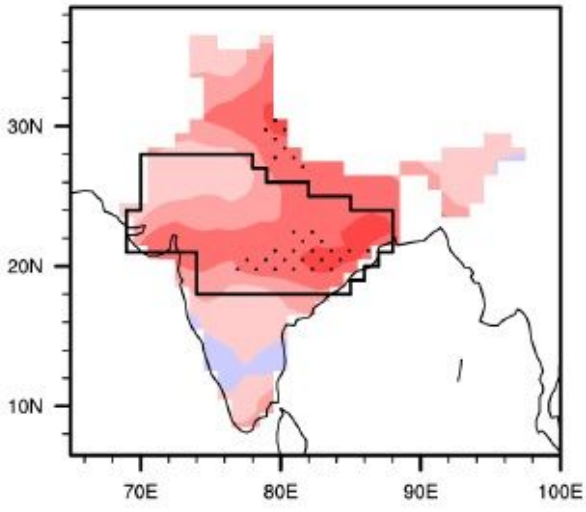

\section{Figure 2}

The multimodel mean of AZM-ISMR teleconnection in the historical simulations (1965-2014) of CMIP6 coupled models. Spatial correlation between the boreal summer central India rainfall anomalies (average of rainfall anomalies over the core monsoon domain) and the SST anomalies (after removing ENSO influence) over the tropical Atlantic. (a) Observations (b) multi-model mean of 12 'good' models (c) multimodel mean of six 'weak' models. (d)-(f) is the same as (a)-(c), but represents the spatial map of correlation between the AZM index and the rainfall anomalies. In observations (panel (a) and (d)) correlation values greater than $95 \%$ confidence levels are stippled. Stippling in panel (b), (c), (e), and (f) denotes that the multimodel mean exceeds 1 standard deviation. 
(a) OBS

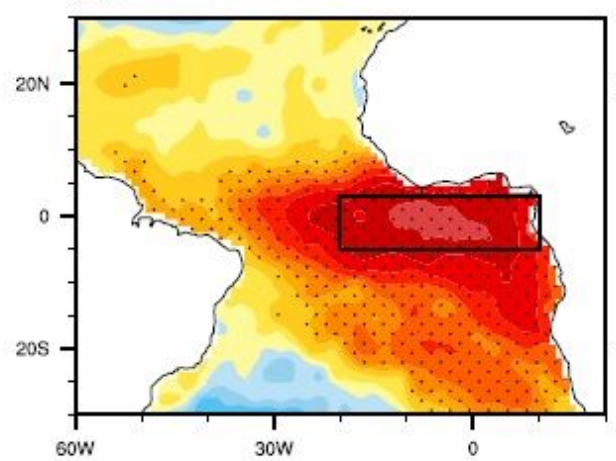

(b) MME of 12 selected models

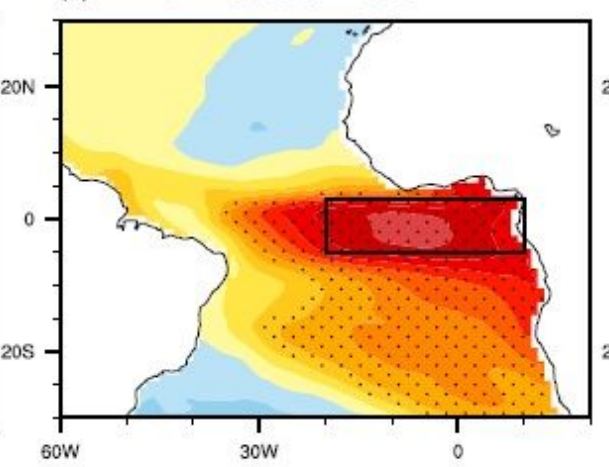

(c) MME of 6 opposite relatlon models

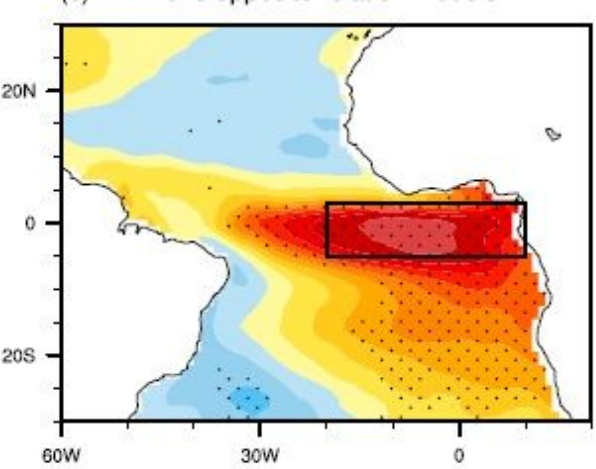

$60 \mathrm{w}$

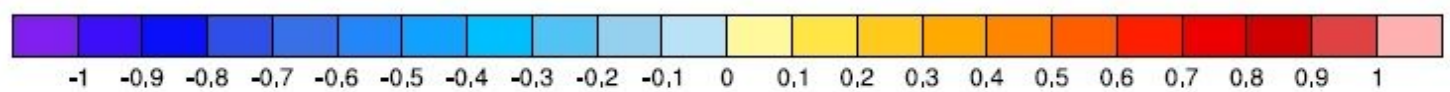

\section{Figure 3}

Spatial correlation between the AZM index and the boreal summer (JJA) SST anomalies over the tropical Atlantic (a) Observations (b) multi-model mean of 12 'good' models (c) multimodel mean of 6 'weak' models. Correlation values greater than $95 \%$ confidence levels are stippled in panel (a). In (b) and (c) stippling denotes that the multimodel mean exceeds 1 standard deviation. 


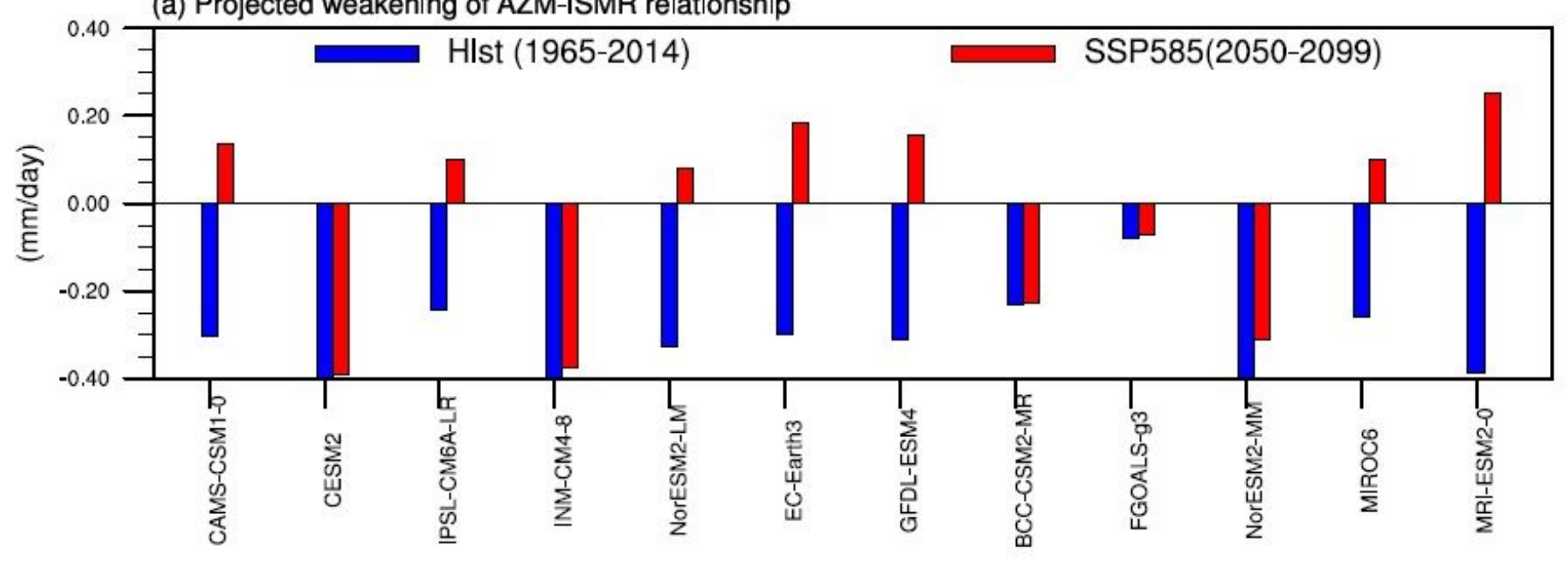

(b) Hist (1965-2014)

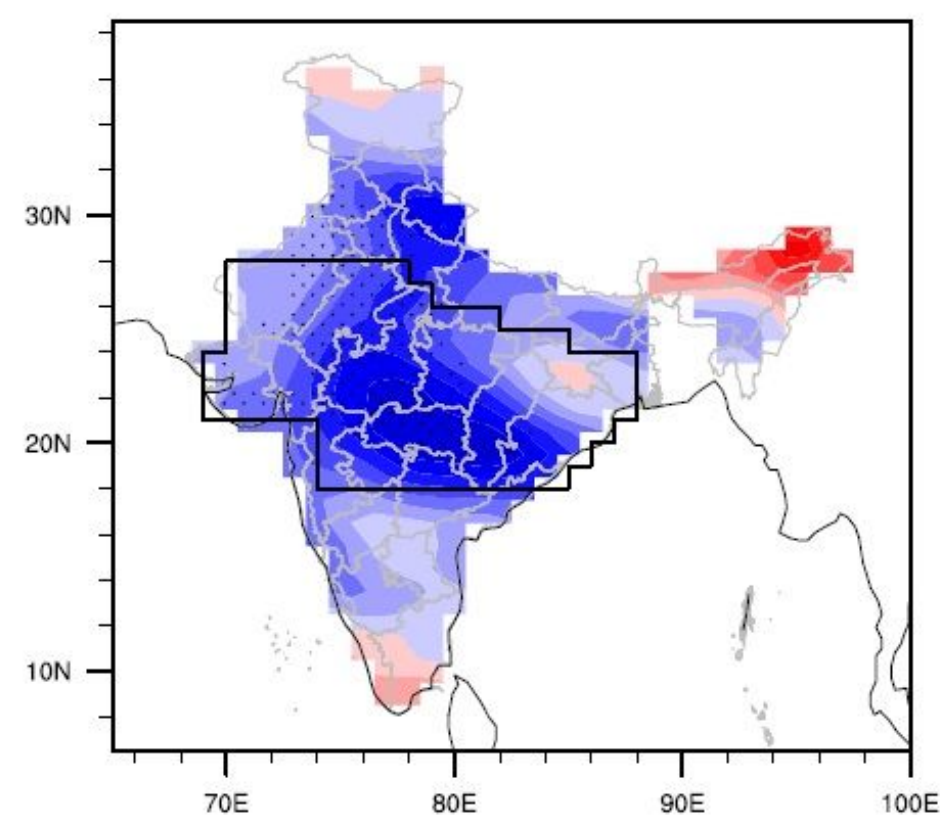

(c) SSP585 (2050-2099)

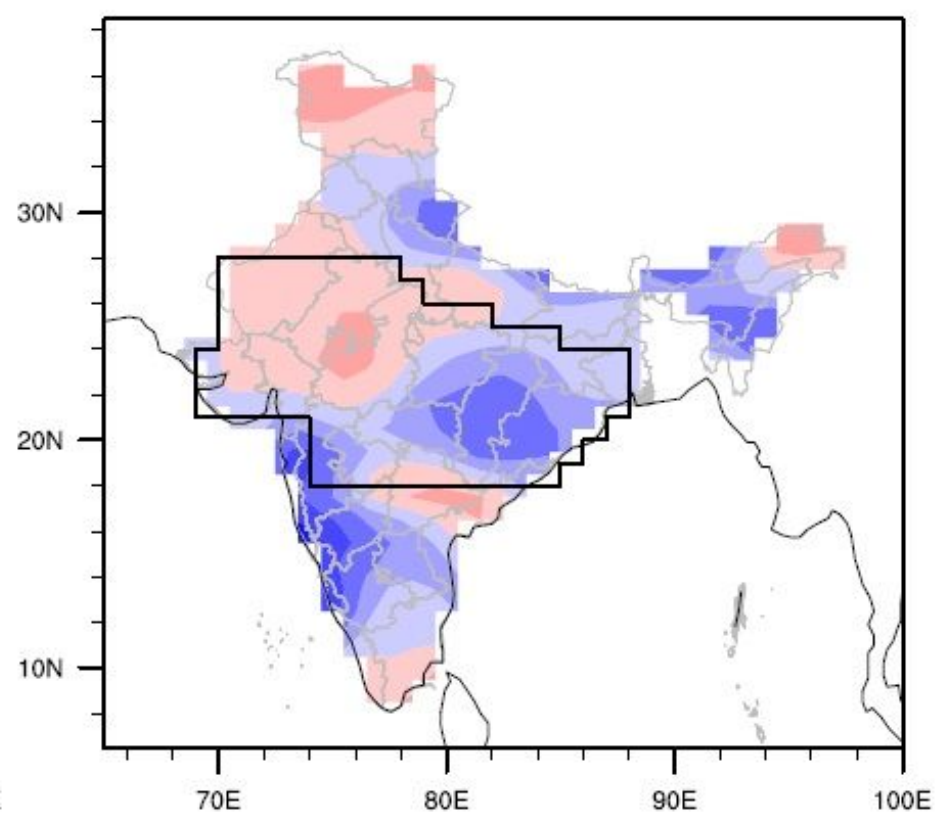

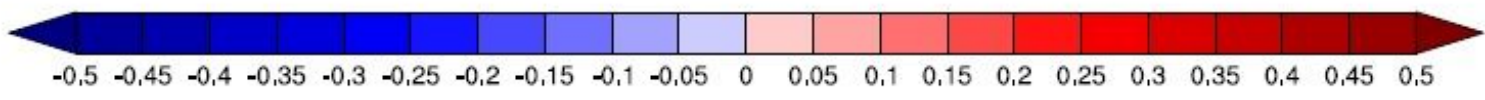

Figure 4

The weakening of AZM-ISMR relationship in a warming scenario. Comparison of central Indian rainfall anomalies due to AZM (ENSO free component of rainfall anomalies) over the historical (blue bars; 19652014) and future (red bars; 2050-2099) in the 12 'good' model simulations. The multimodel mean of the regression coefficients over the Indian subcontinent in (b) historical and (c) future simulations. Stippling in (b) and (c) denotes that the multimodel mean exceeds 1 standard deviation. The regression analysis is carried out between the AZM index and the boreal summer rainfall anomalies (after removing ENSO influence). 
(a) Hist (1965-2014)

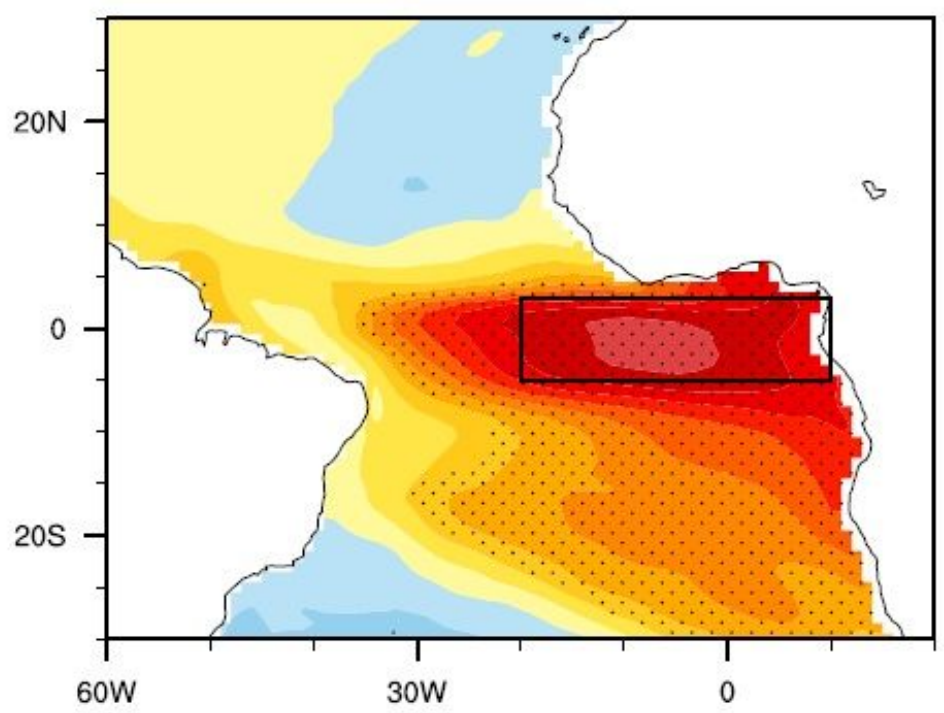

(b) SSP585 (2050-2099) MME selected models

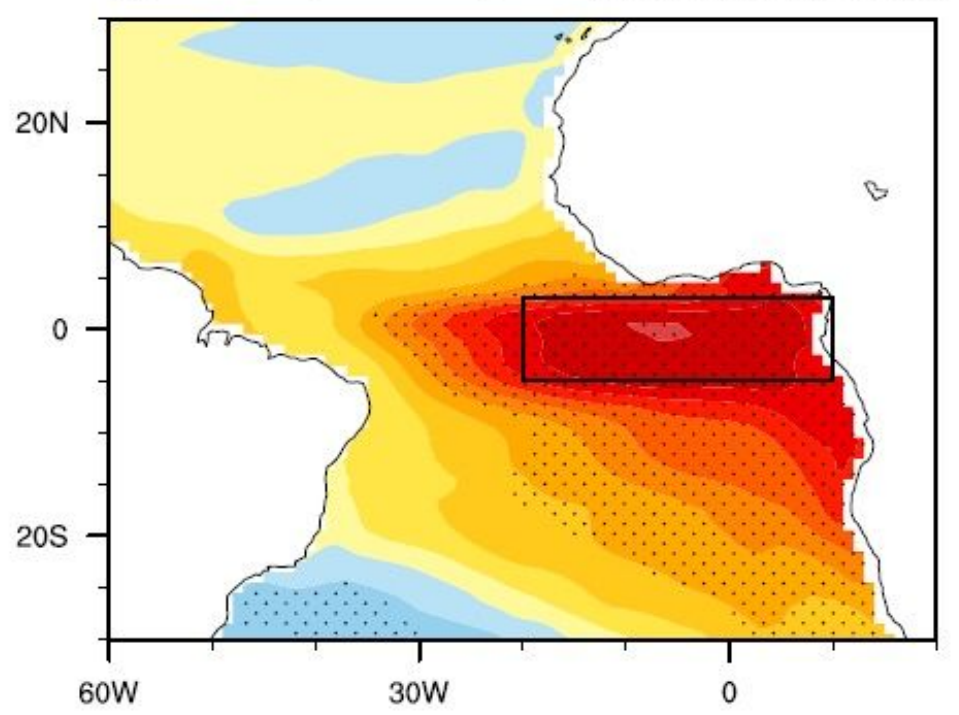

(c)

Cor $=0.03$

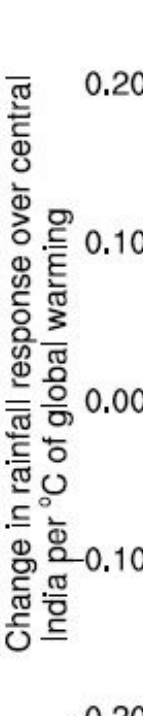

$-0.20$

$\begin{array}{lllll}-0.040 & -0.020 & 0.000 & 0.020 & 0.040\end{array}$

Change in AZM amplitude per ${ }^{\circ} \mathrm{C}$ of global warming

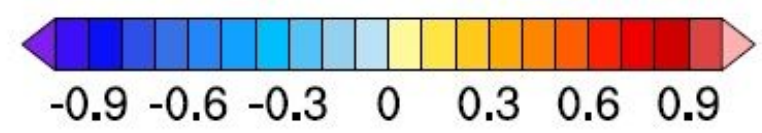

MRI-ESM2-0

MIROC6

NorESM2-MM

FGOALS-g3

BCC-CSM2-MR

GFDL-ESM4

EC-Earth3

NorESM2-LM

INM-CM4-8

IPSL-CM6A-LR

CESM2

CAMS-CSM1-0

\section{Figure 5}

Impact of AZM amplitude change on the rainfall response over India from the selected 12 CMIP6 models. Spatial correlation between the AZM index and JJA SST anomalies (a) historical (b) SSP5-8.5 simulations. Stippling in (a) and (b) denotes that the multimodel mean exceeds 1 standard deviation. (c) Intermodel relationship between AZM amplitude change (future historical; X-Axis) and the changes in rainfall response over central India (future-historical; $Y$-axis). The black solid line represent the linear trend line. The correlation coefficient between changes in AZM amplitude and the changes in rainfall response over central India is also given in the top right corner. For a better comparison, the changes are scaled by the increase in global-mean temperature over the historical and future period. The AZM amplitude is computed by area-averaging the regressed SST anomalies (onto AZM index) in the eastern equatorial 
Atlantic (5oS-3oN, 20oW- $10 \circ \mathrm{oE})$. Similarly, the rainfall response over central India is obtained by areaaveraging the regressed rainfall anomalies (onto AZM index).
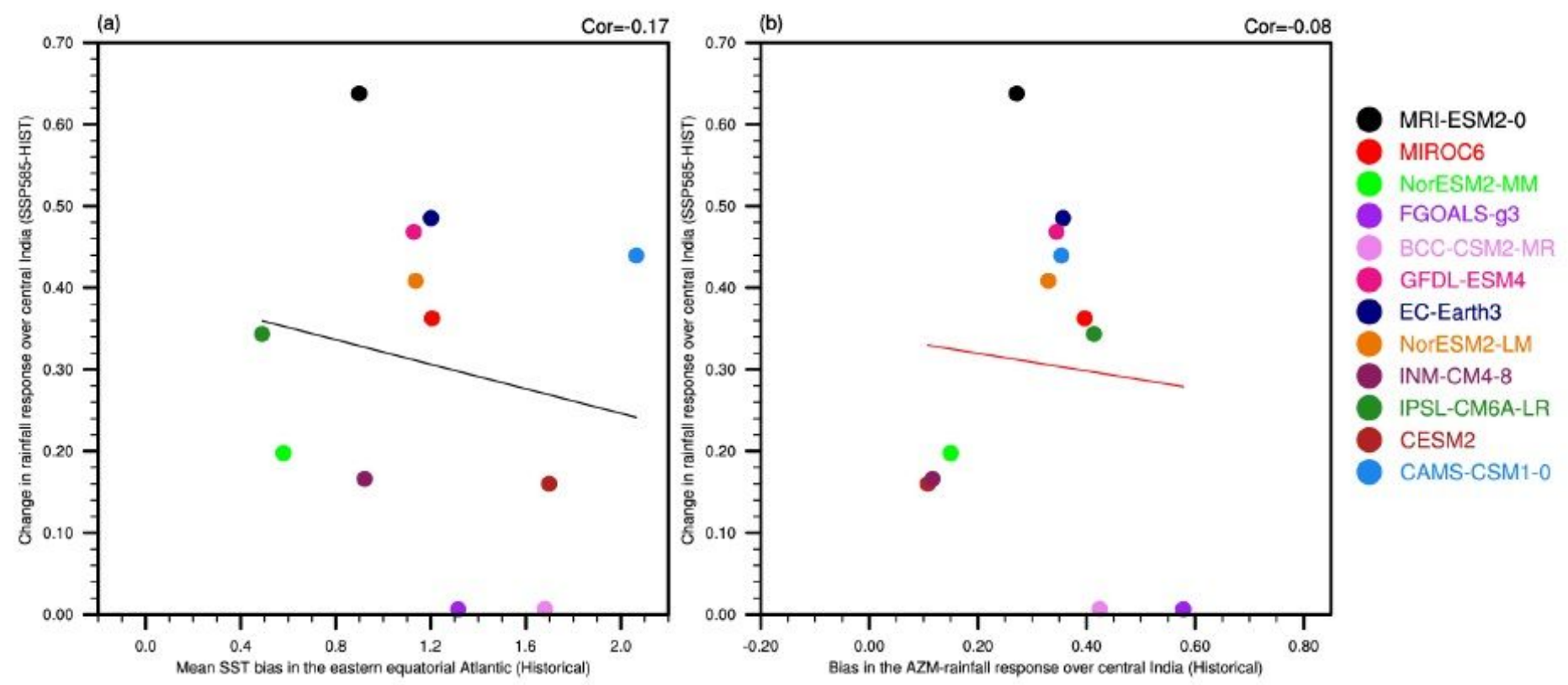

\section{Figure 6}

Impact of model biases on the projection of rainfall responses over India. Intermodel relationship between the (a) mean SST (OC) bias in the eastern equatorial Atlantic (5oS-3oN, 20oW-10oE) and the changes (future-historical) in rainfall ( $\mathrm{mm} /$ day) response over central India (b) biases in simulating AZMISMR teleconnection and the changes (future-historical) in rainfall response over central India. The rainfall response over central India is obtained by area-averaging the regressed rainfall anomalies onto AZM indices. The mean Atlantic SST bias in each model is obtained by the difference of climatological mean SST over the eastern equatorial Atlantic during the historical period between model and observations. Similarly, the biases in simulating AZM-ISMR teleconnection are obtained by taking the difference of rainfall response over central India during the historical period between model and observations. The solid lines in (a) and (b) represents the trend line and correlation coefficients are denoted in the top right corner of each panel. 

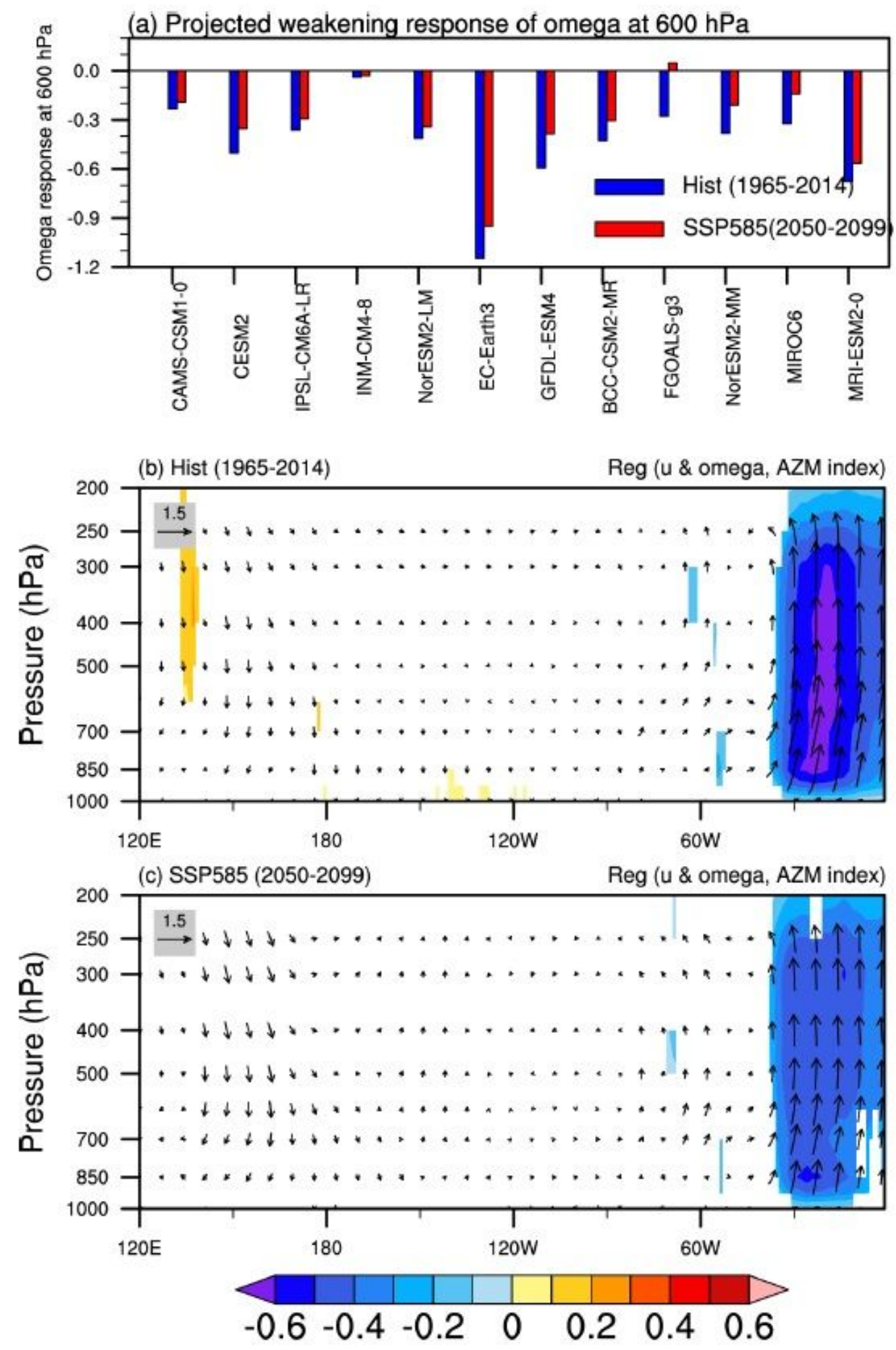

\section{Figure 7}

Future weakening of the convective response to the AZM over the eastern equatorial Atlantic. (a) The 600 $\mathrm{hPa}$ vertical velocity (Pa So1) response to the AZM averaged over the eastern equatorial Atlantic (5oS$30 \mathrm{~N}, 20 \mathrm{oW}-10 \mathrm{oE}$ ) in historical (blue bars) and future (red bars) simulations. Multimodel mean of the regression coefficients of the equatorial $(50 \mathrm{O}-5 \mathrm{oN})$ atmospheric vertical velocity and the ow vectors 
(mso1) onto the AZM index in (b) historical (c) future period. Shading represents multi-model mean exceeding 1 standard deviation in (b) and (c).

(a) JJA mean alr temperature diff (SSP585-Hlst)
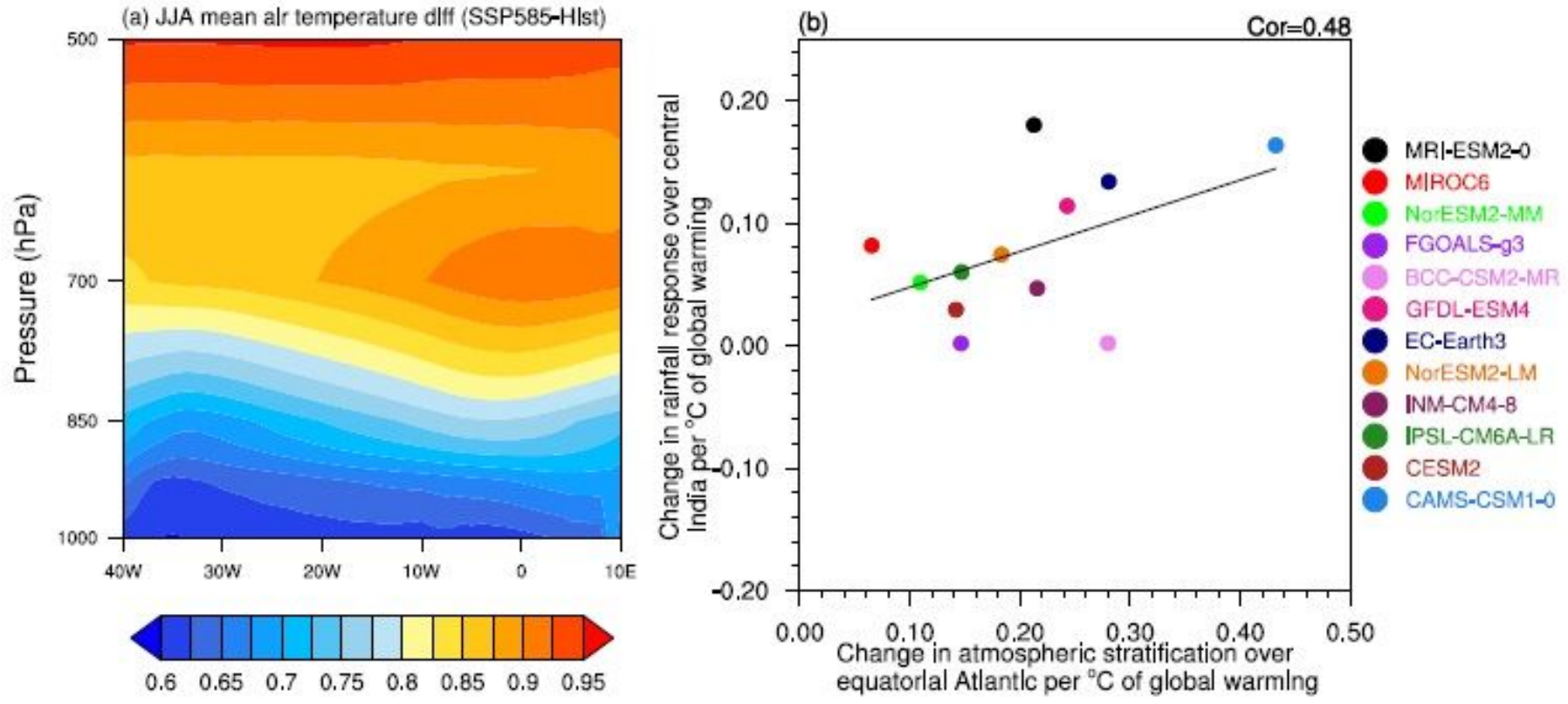

\section{Figure 8}

Impact of increased atmospheric thermal stability on the projected weakening of AZM-ISMR relationship in future. The difference of JJA mean air temperature (OC) between the future and historical period (SSP5-8.5-historical) over the equatorial Atlantic (averaged over 5oS-5oN). Intermodel relationship between the changes (future-historical) in boreal summer atmospheric stratication (X-Axis; units: $0 \mathrm{C}=0 \mathrm{C}$ ) and the rainfall response over central India (Yaxis; units: mmdayo1=0C). The black solid line represent the linear trend line. The atmospheric stratication is dened as the difference between the atmospheric temperature at $600 \mathrm{hPa}$ and $925 \mathrm{hPa}$ averaged over the eastern equatorial Atlantic. The changes in both panels are scaled by the increase in global-mean temperature. 
(a) Hist (1965-2014) 200 hPa vp(shaded) 200 hPa Div. wnd(vector)

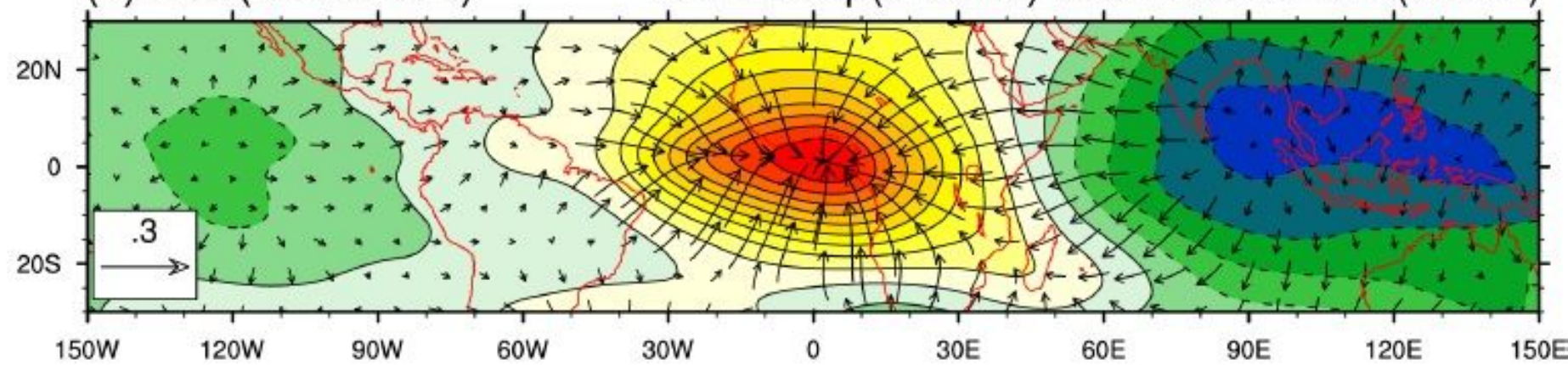

(b) SSP585 (2050-2099) $200 \mathrm{hPa}$ vp(shaded) $200 \mathrm{hPa}$ Div. wnd(vector)
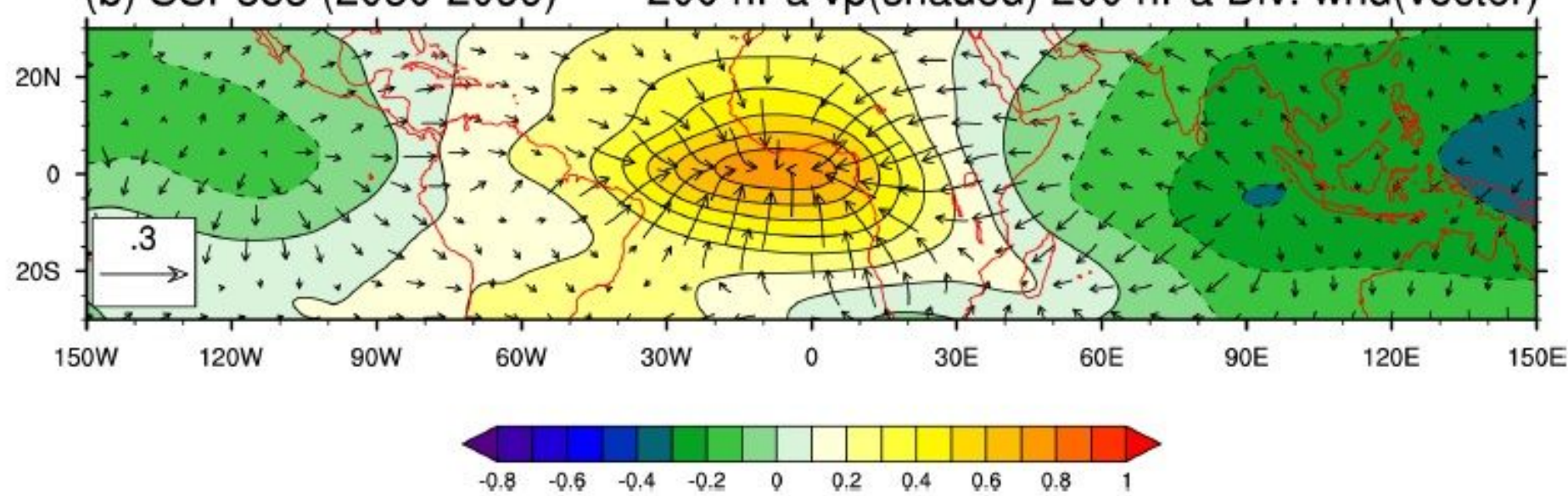

Figure 9

The weakening of velocity potential response over India in the warming scenario. The multimodel mean of the regression coefficients of $200 \mathrm{hPa}$ velocity potential (contour) and divergent wind (vector) in (a) historical (b) SSP5-8.5 simulations. Negative (positive) contour indicates the upper-level divergence (convergence). Shading represents multimodel means above 1 standard deviation. The regression analysis is carried out between the parameters (200 hPa velocity potential and divergent winds) and the AZM index (multiplied by -1; units: $106 \mathrm{~m} 2$ so1 per standard deviation of the regression index). 
(a) Hist (1965-2014)

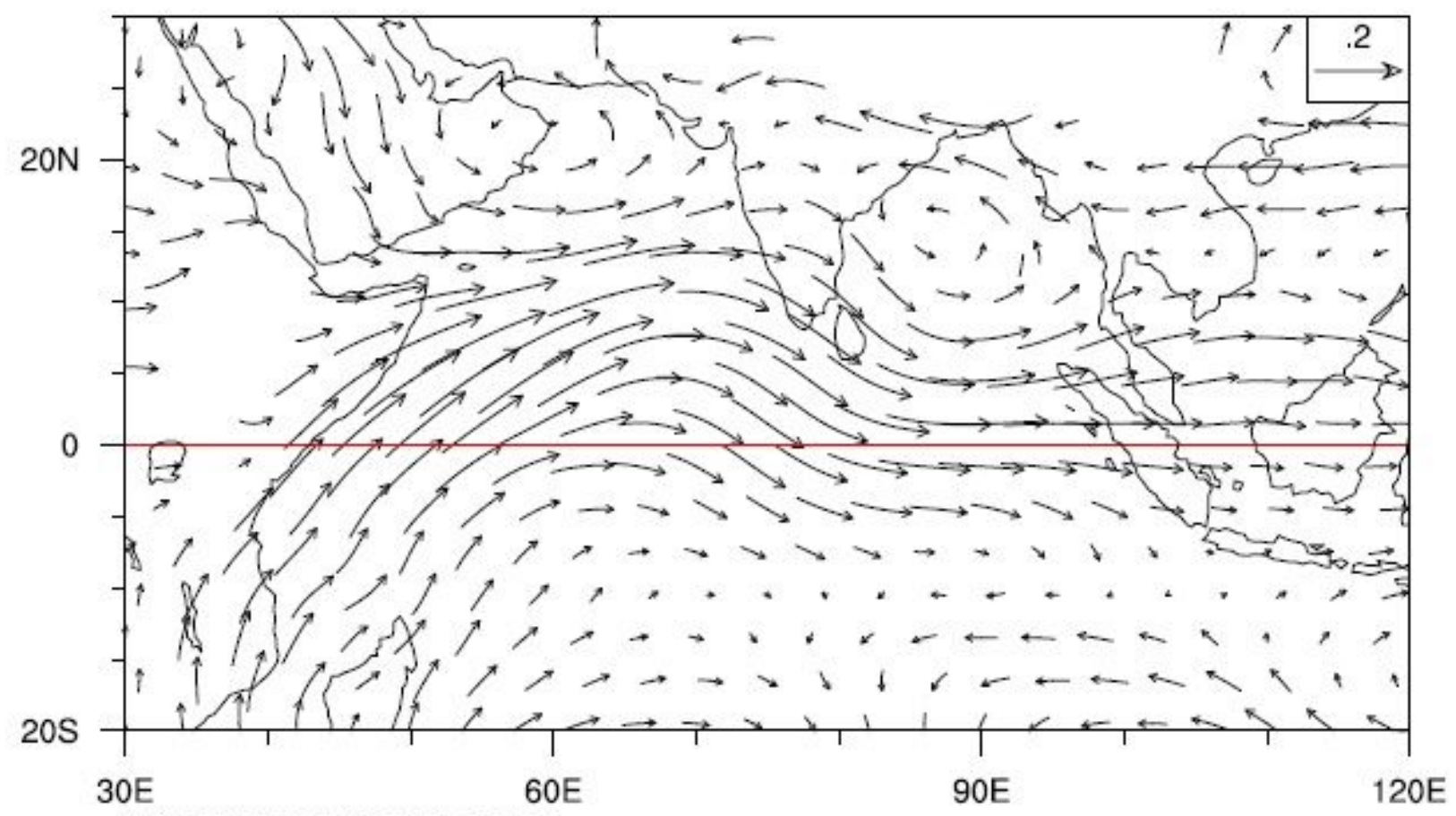

(b) SSP585 (2050-2099)

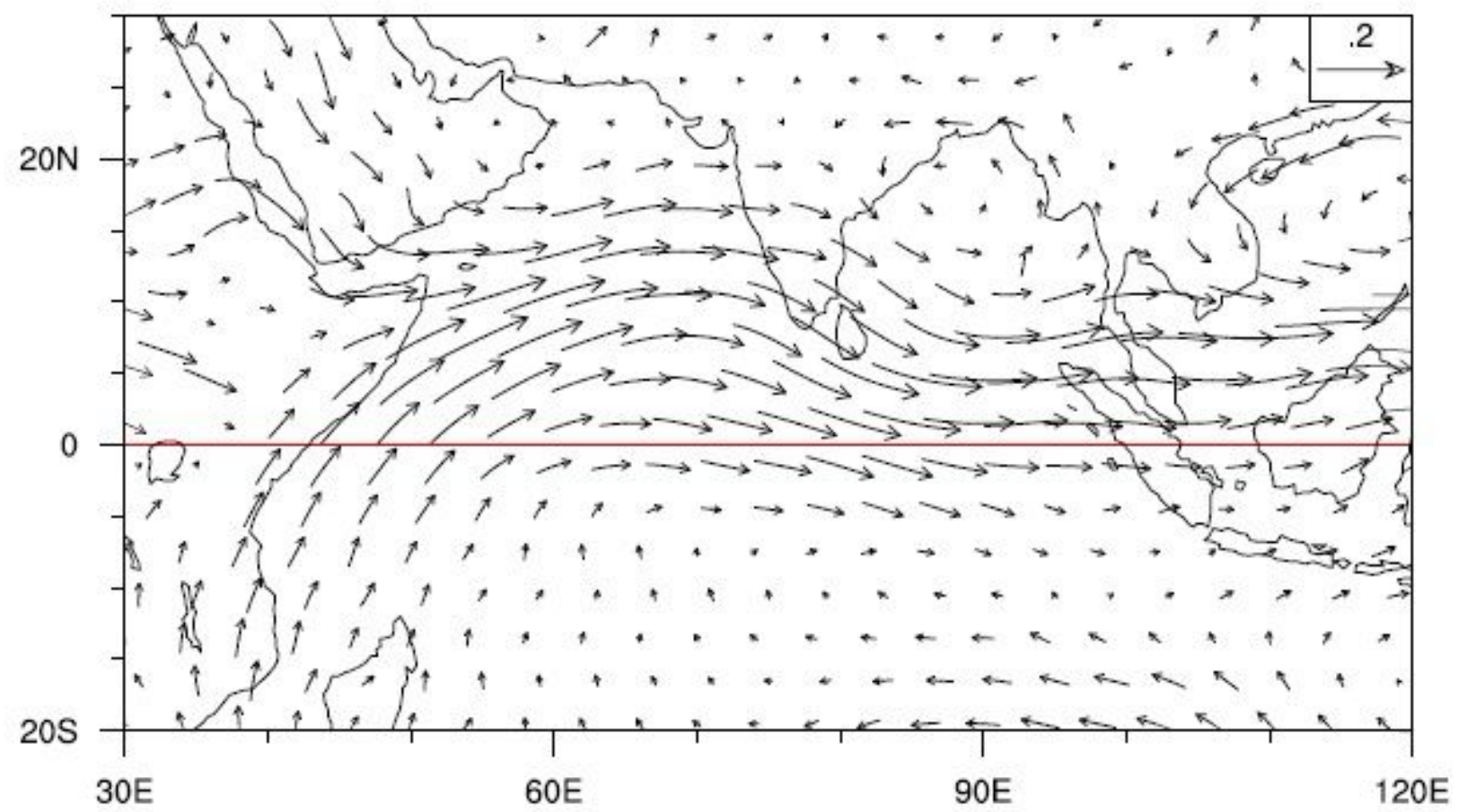

Figure 10

The weakening of low-level wind response over central India in the warming scenario. The multimodel mean of the regression coefficients of mean low-level $(850 \mathrm{hPa})$ wind anomalies in (a) historical and (b) SSP5-8.5 simulations. The regression analysis is carried out between $850 \mathrm{hPa}$ wind anomalies and the AZM index (multiplied by -1 ; units: mso1 per standard deviation of the regression index). 